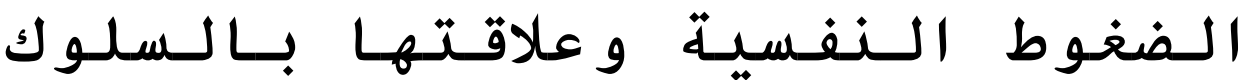

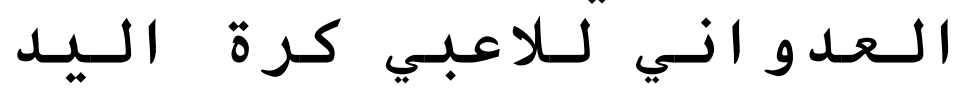

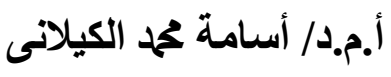

أستاذ مساعد علم النفس الرياضى و القائم بعمل رئيس

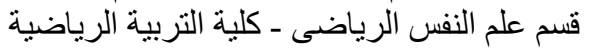

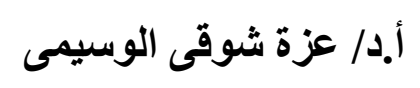

أستاذ علم النفس الرياضي و عميد كلية التربية

الرياضية السابق - جامعةٌ طنطا لرئ
هيثم عبدالغنى حمح عكر

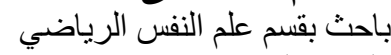

كلية التربية الرياضية - جامعة طنطي
د/ هدير محمد المطاهر

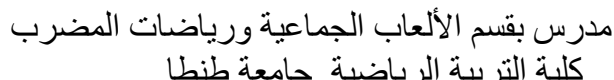




\section{الضغوط النفسية وعلاقتها بالسلوك العدواني للاعبي كرة اليد}

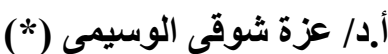

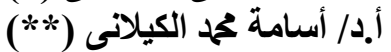

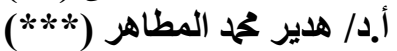

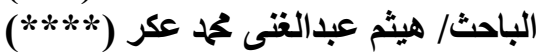

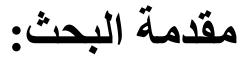

تعتبر الضغوط النفسية ظاهرة الضغوط من أكثر الظواهر اهتماماً لأهميتها على مستوى الفرد

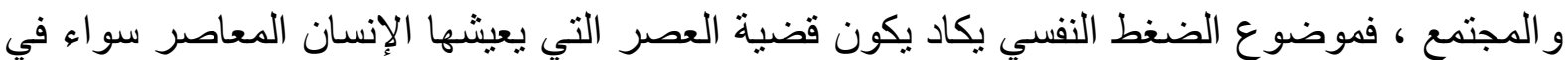
المجتمعات المتقدمة أو النامية حتى يكاد يخلو من أثنار ها ونتائجها "طفل أو مر اهق أو أو ر اثند في مجالات التهات

( الحياة . (

تعد ظاهرة الضغوط النفسية أحد ظواهر العصر الحديث ، و أحد الظواهر النفسية المؤثرة على في

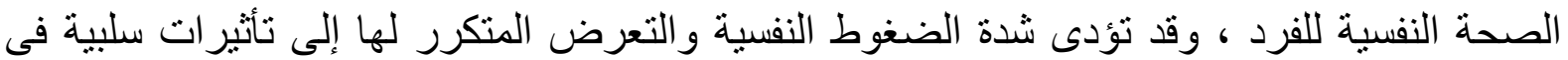
شخصية الفرد و إلى خلل فى الصحة النفسية ، مما قد يؤثر على صحة الفرد ، وقد يصل الأمر الى الإنهاك

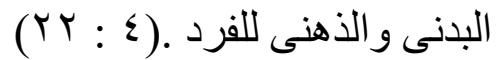

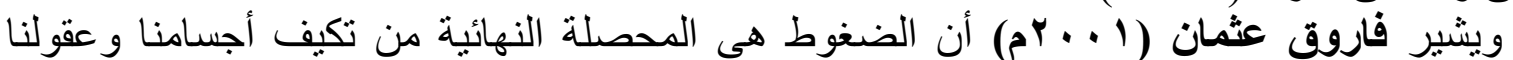
للتغير الذي يتطلب جهداً جسدياً ونفسياً وانفعالياً سو اء بالنسبة للأحداث السلبية أو حتى الأحداث الإيجابية

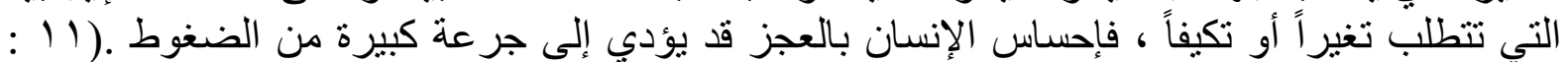

و ولا شك أن الضغوط نؤثر على الإنتاجية ، ويتجلى ذلك في نسب تغيب العاملين عن العمل، وفي

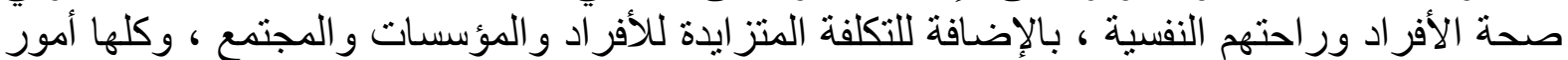

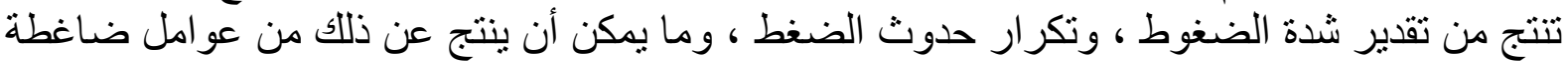

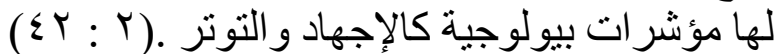

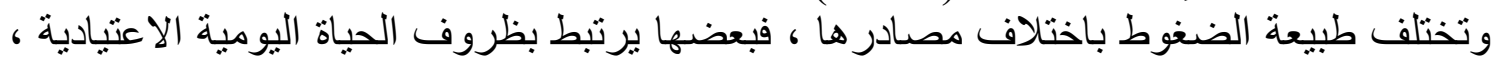

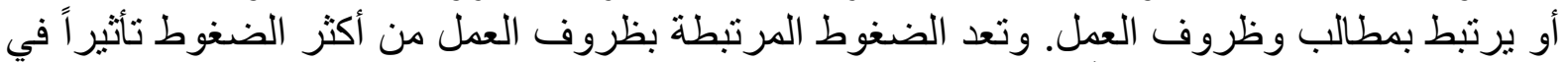
حياة الأفر اد و المجتمعات، نظر اً لأثار ها السلبية على الصحة النفية النفية للفرد و وعلاقاته مع الآخرين، وتدني

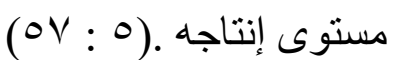
ويعتبر العدوان أحد الصفات المميزة للسلوك الإنسانى التى منحها الله عز وجل لكل إنسان وبهذه

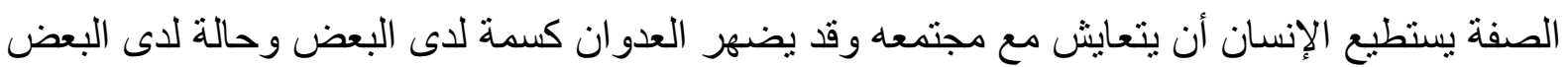

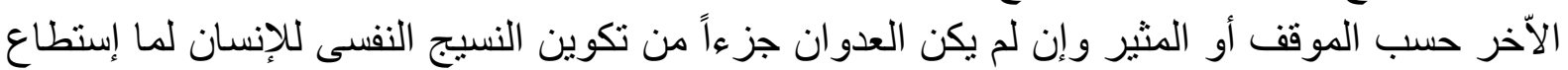

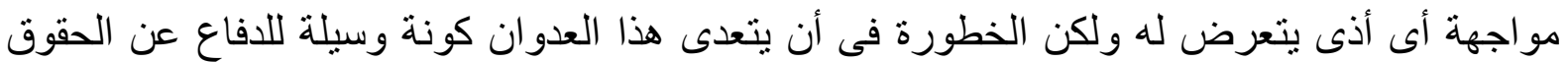

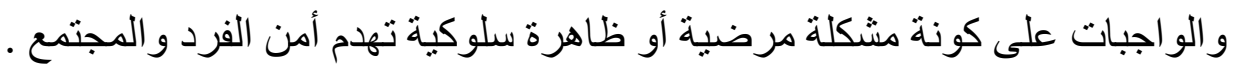
ويعد السلوك العدو انى أحدى المظاهر السلوكية الثائعة التى حظيت بالإهتمام والدراسة ، فهو مفهوم غامض تتعدد معانيه ، وتتداخل الأسباب التى تمهذ له وتتنوع النظريات المفسرة لماهيته ، فعلماء التربية

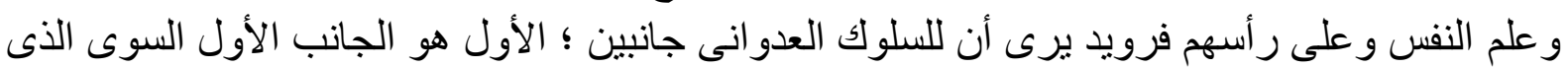

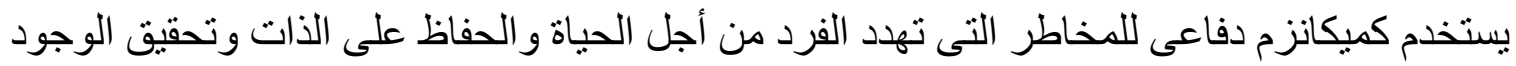


، ويستخدمه كوسيلة للافاع عن نفسه وممتلكاته و إز الة العقبات التى تحول دون تحقيق أهدافه ، فهو

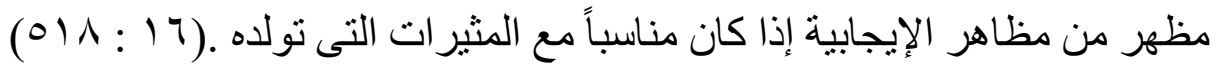
أما الجانب الثانى ؛ هو الجانب الغير سوى الهام الذّى يستخدم عن وعى أو غير وعى كسلاح يعمل

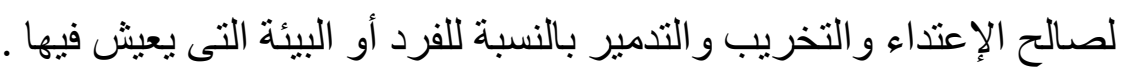

(17V: 9)

ويرى روزنبلت شاهال Rozenblatt Shahal (r . . rم) أن السلوك العدوانى هو كل سلوك ينتج عنه إيذاء لثخص آخر أو إتلاف لثئ ما ، وبالتالى السلوك التخريبى هو شكل من اشكال العدوان (VY: الموجه نحو الأشياء. (N)

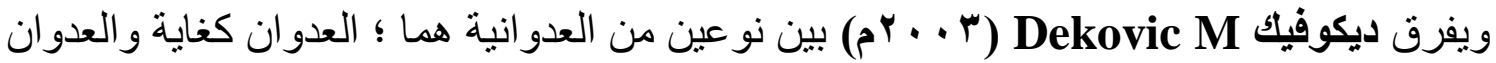
كوسيلة على أساس أن هدف النوع الأول هو الإيذاء للغير أما الثانى فإبعاد خطر المنافس بإذائه ، وأن النوعين السابقين من السلوك العدو انى هما من نوع العدوان السلبى غير المر غوب فيه ، نظر اً لأن القصد منهما هو الإيزاء وإلحاق الضرر ، ويقام نوعاً آخر بطلق عليه السلوك العدوانى الإيجابى أو السلوك لكأل

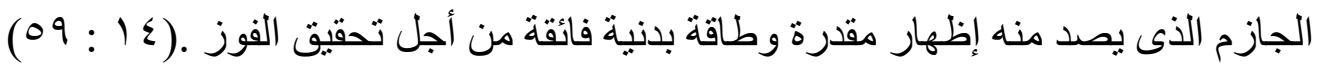

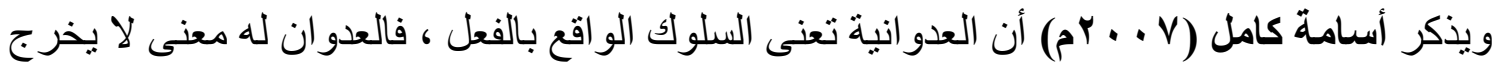

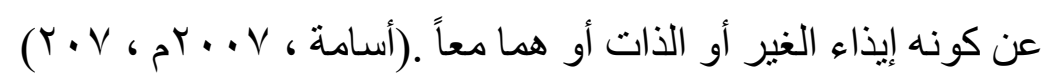

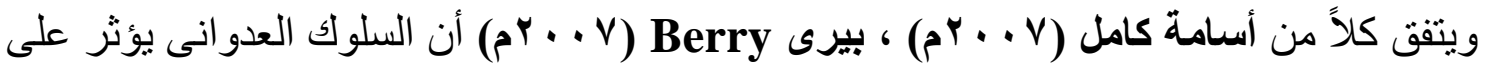

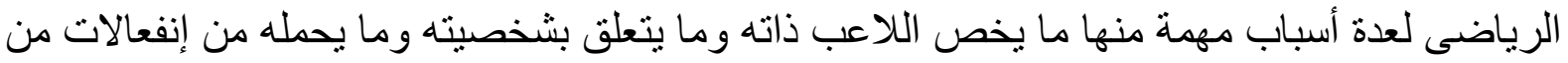

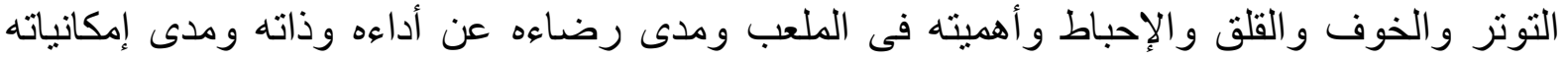

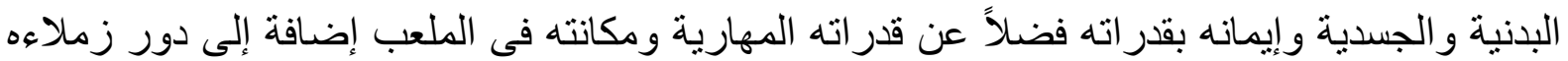

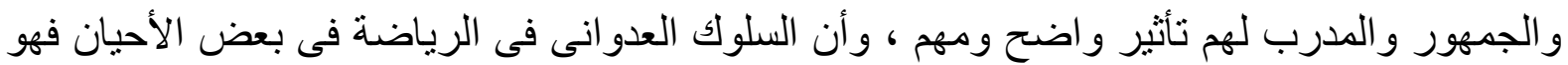

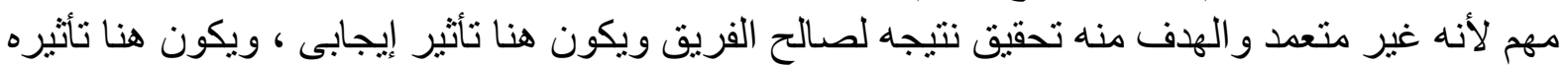

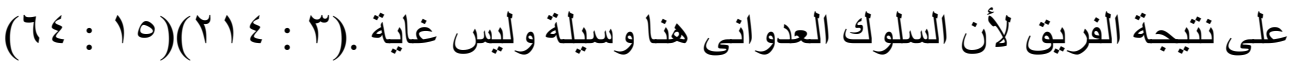
وكرة اليد من الرياضات ذات الثعبية العالمية فهي تعد اللعبة الأولي في الكثير من بلدان العالم

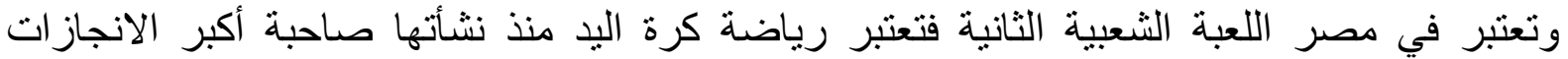

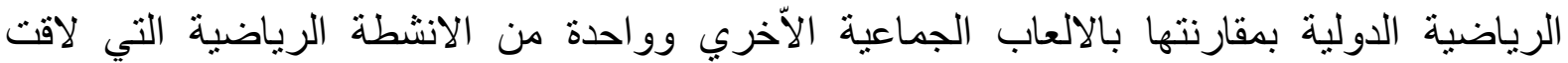

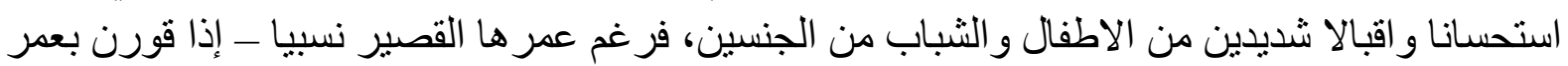

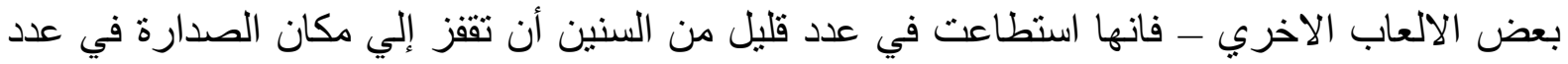

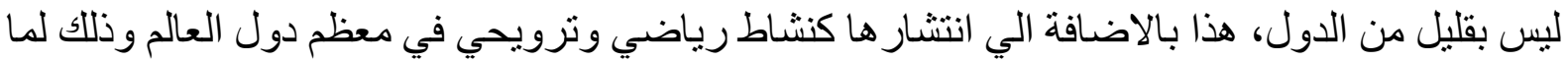

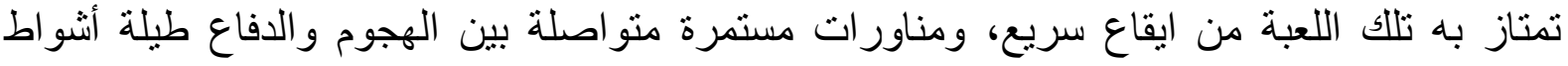

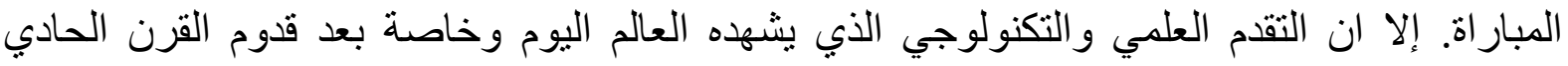

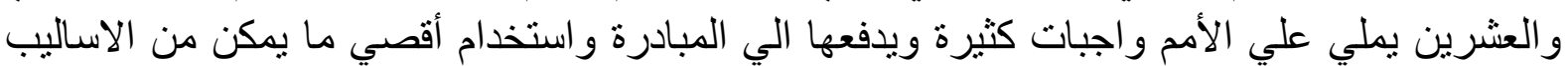


التكنولوجية المعاصرة وكذلك تطوير أساليب التعليم بحيث تتخلص من النظم التقليدية من أجل مواكبة

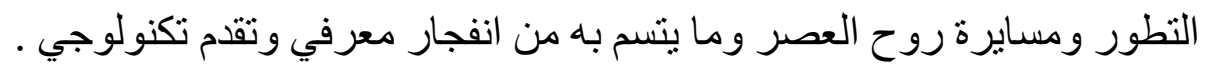

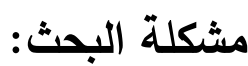

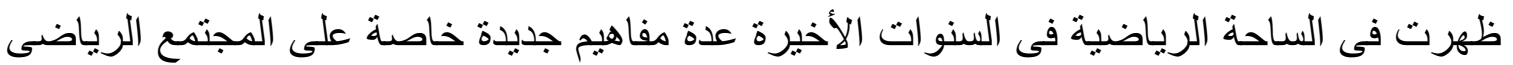

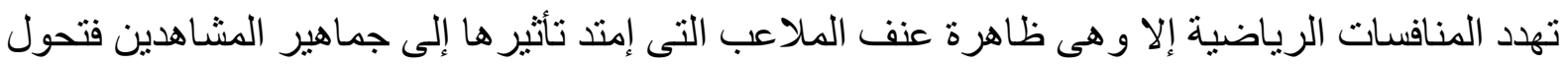

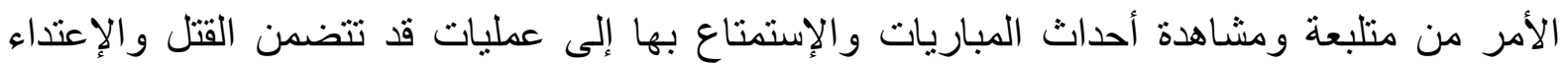

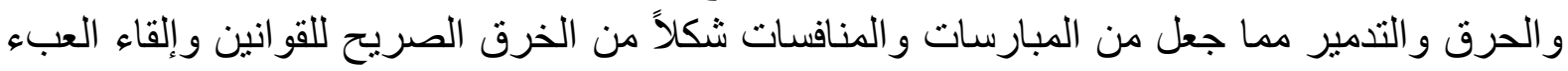

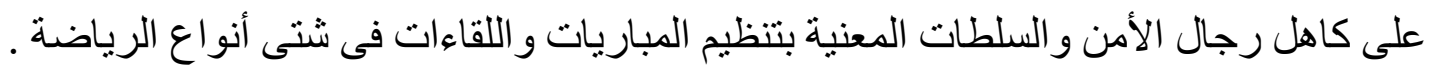

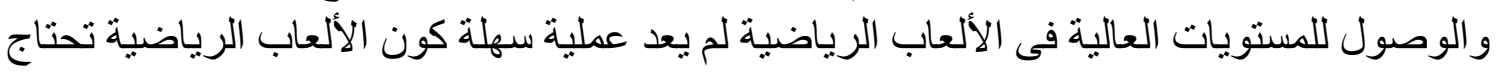

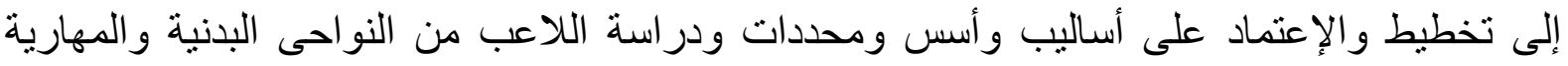

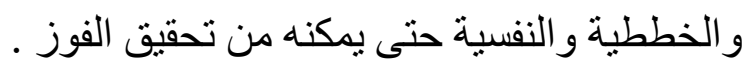

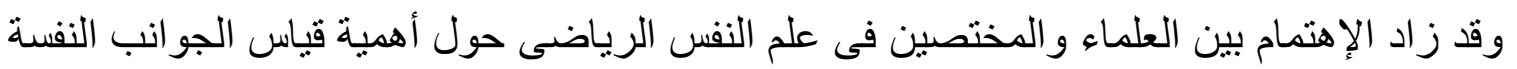

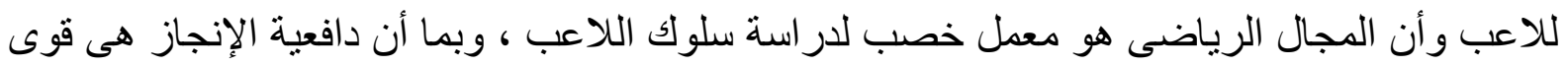

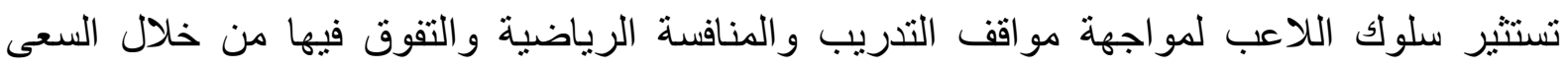

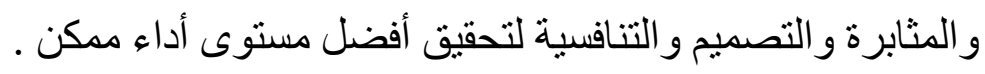

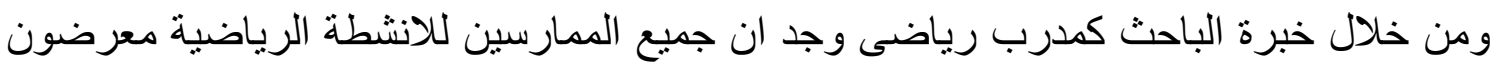

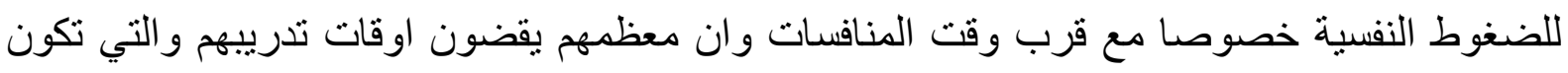

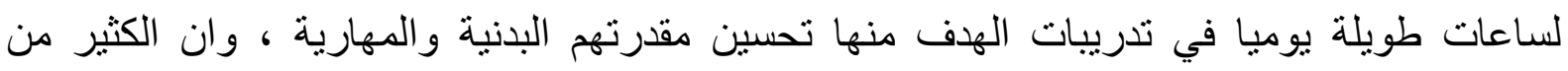

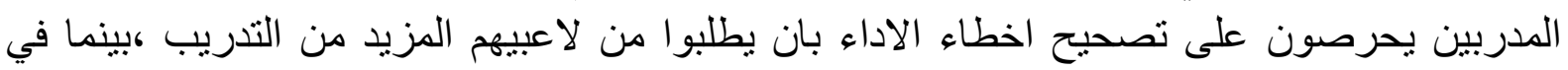

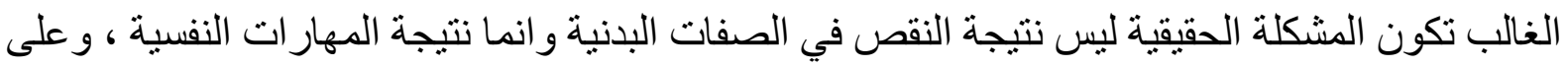

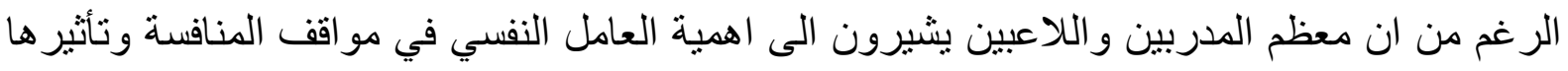

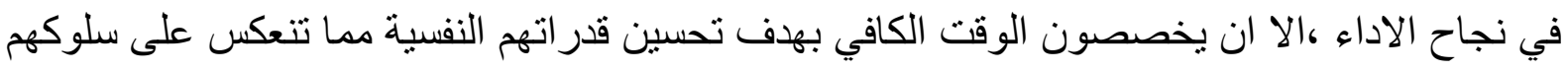

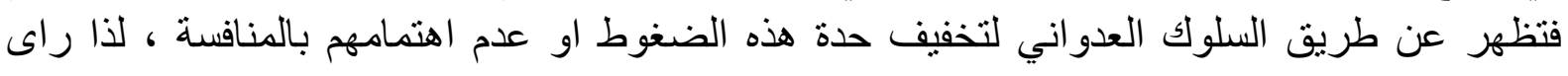

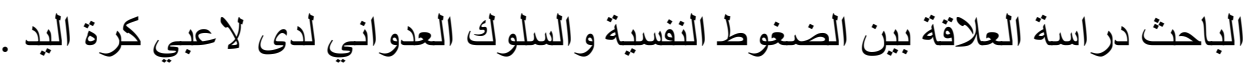

هدف البحث: التعرف على الضغوط النفسية وعلاقتها بالسلوك العدو اني للاعبي كرة اليد

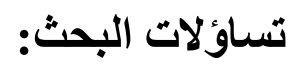

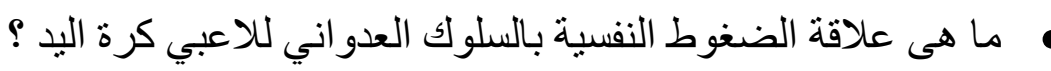

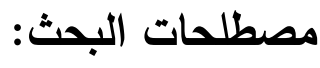
الضغوط النفسية : الضفات

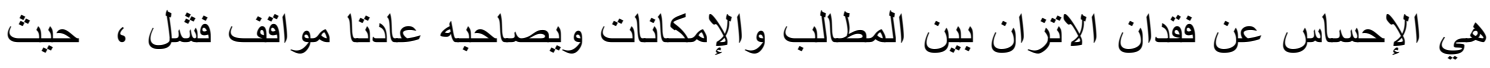

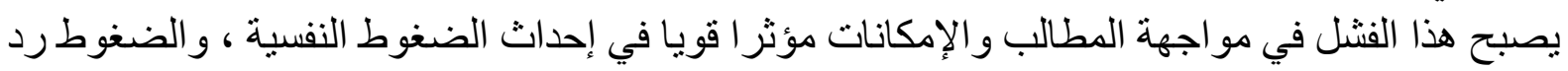

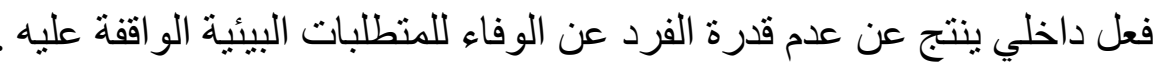

$(r q: 1 v)$ 


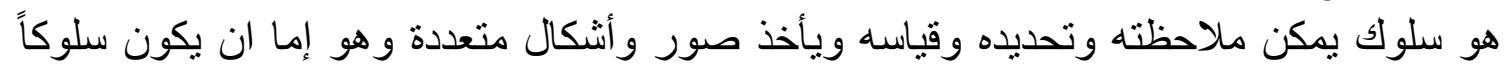

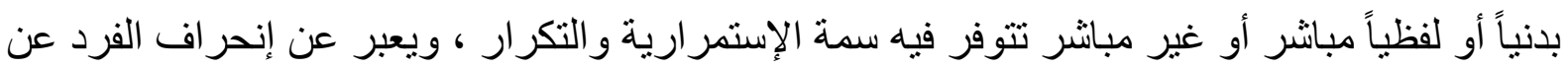

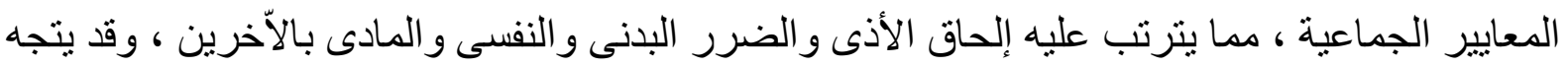

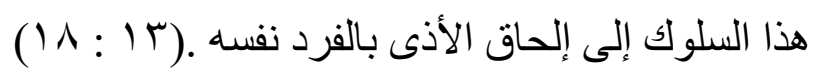

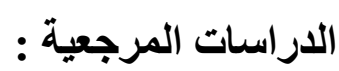

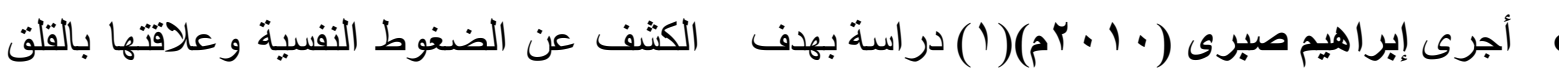

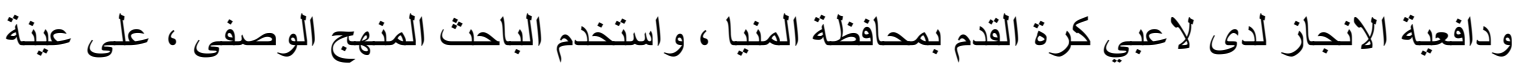

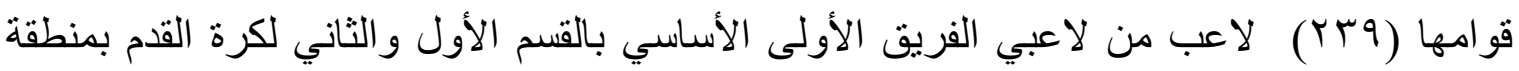

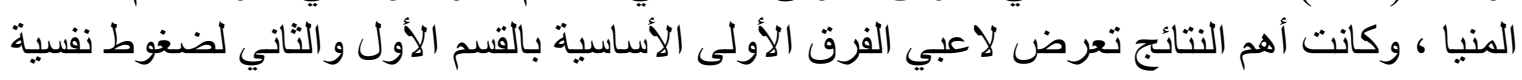

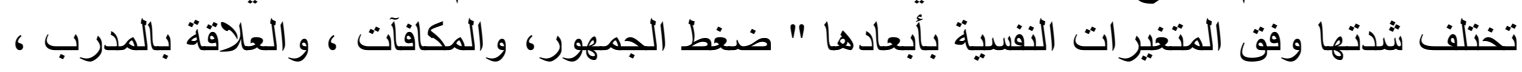

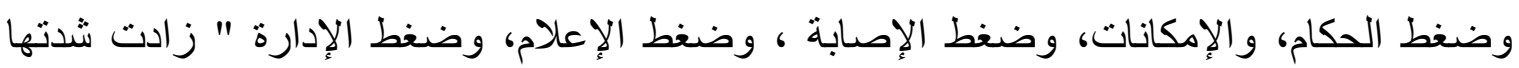

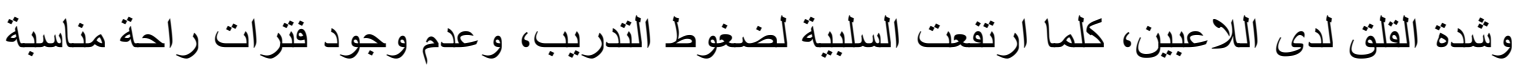

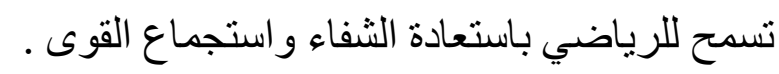

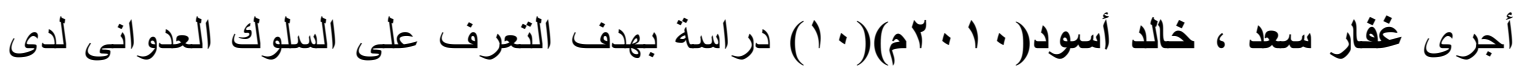

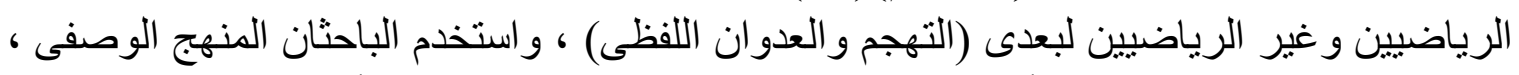

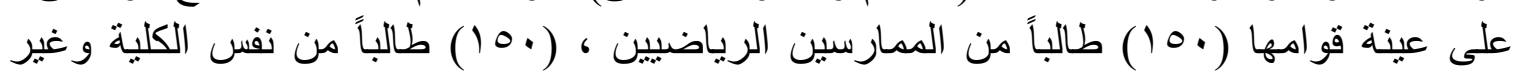

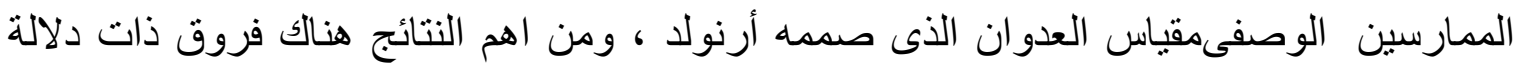

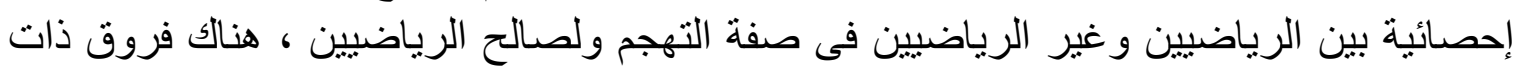

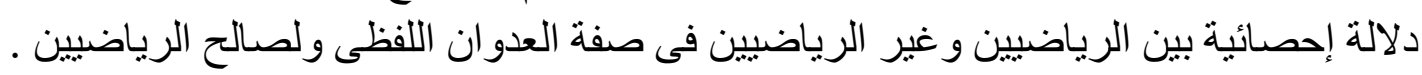

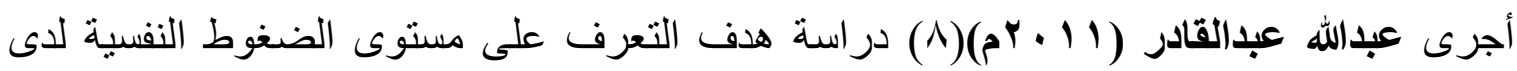

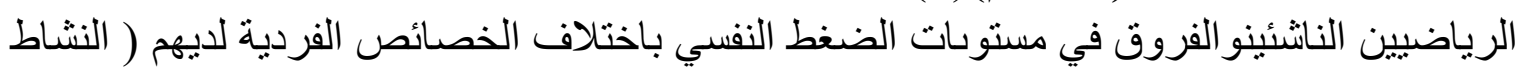

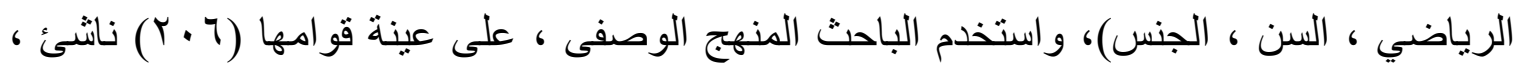

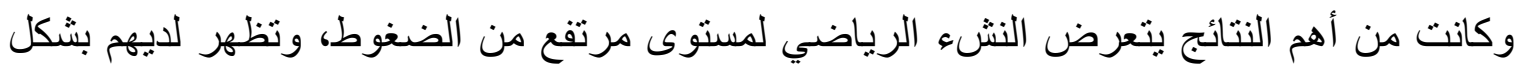

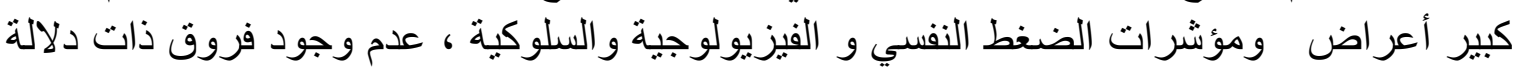

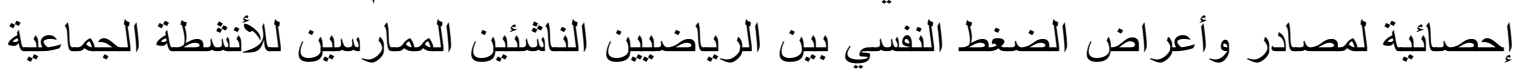

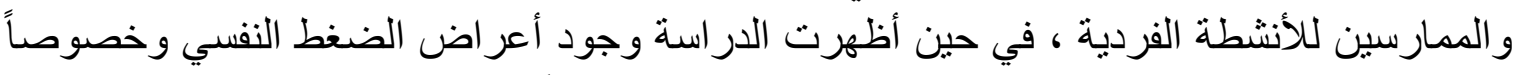

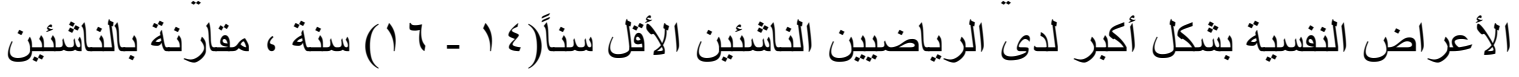

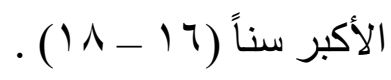

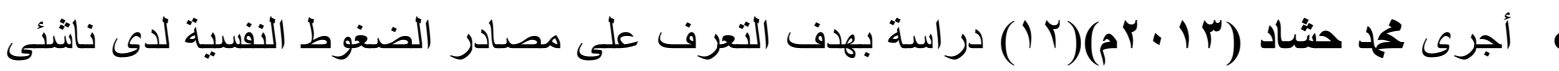

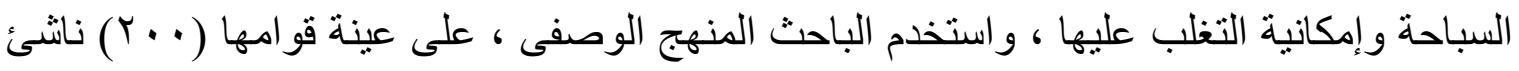

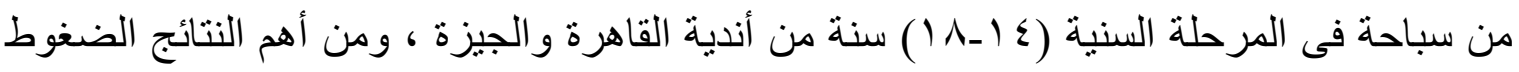

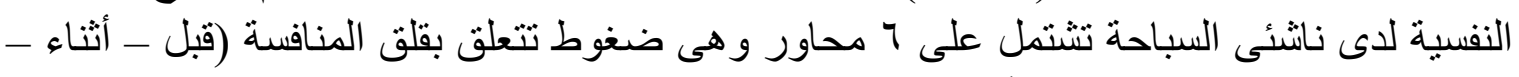

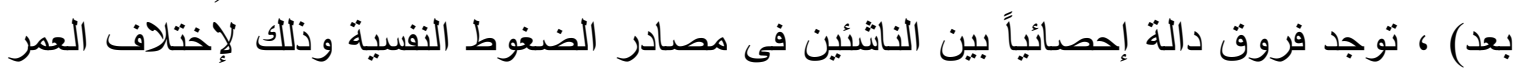
الزمنى - العمر التدريبى - مدى تحقق النتائج . 


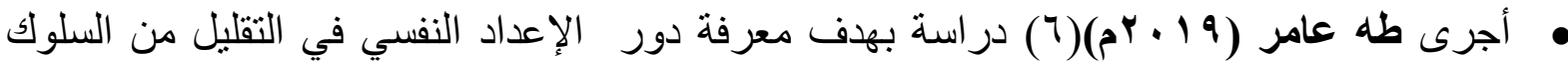

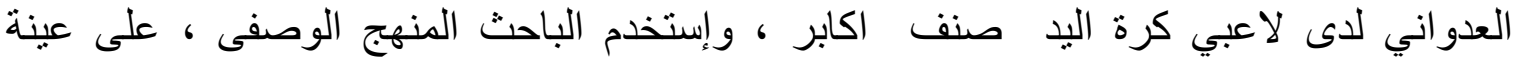

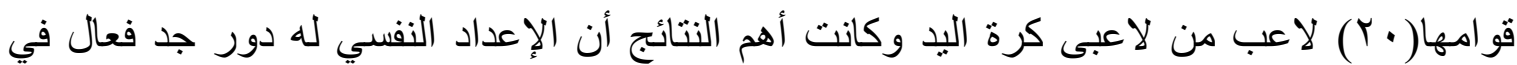

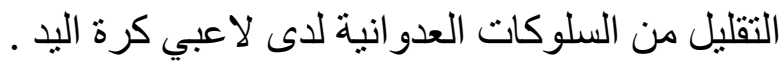

إجراءات البحث

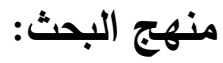

استخدم الباحث المنهج الوصفي بخطو اته ، وإجر اءاته وذذلك لملائمته لطبيعة البحث.

مجتمع وعينة البحث

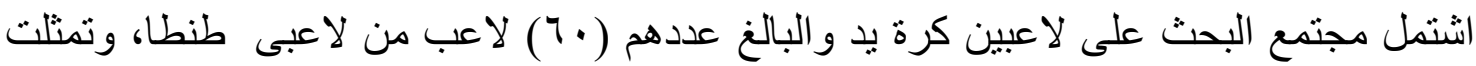

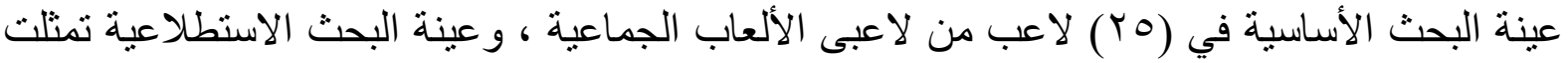

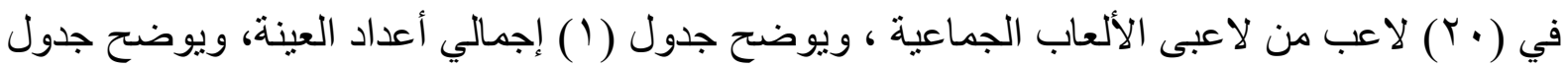

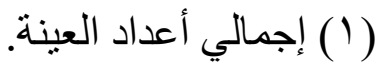

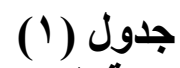

إعداد عينة البحث الكلية (الأساسية والاستطلاعية)

\begin{tabular}{|c|c|c|c|c|c|c|c|}
\hline \multicolumn{2}{|c|}{ المستبعدون } & \multicolumn{2}{|c|}{ العينة الاستطلاعية } & \multicolumn{2}{|c|}{ العينة الأساسية } & \multicolumn{2}{|c|}{ مجتمع البحث } \\
\hline النسبة & العدد & النسبة & العدد & النسبة & العدد & النسبة & العدد \\
\hline$\%$ Yo & 10 & אי. & r. & $\% \leqslant 1.77$ & ro & $\% 1 \ldots$ & 7. \\
\hline
\end{tabular}

تجانس عينة البحث فى المتغيرات الأساسية :

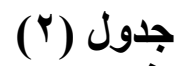

الالالات الاحصائية لافر اد عينة البحث فى المتفيرات الاساسية لبيان اعتدالية البيانات

\begin{tabular}{|c|c|c|c|c|c|c|c|}
\hline الالتواء & التقلطح & المعيارى الأحراف & الوسيط & الحسابي & القياس & المتغيرات & p \\
\hline & & & & & & معدلات دلالات النمو & \\
\hline$\cdot r \cdot \varepsilon$ & 1.0 .1 & $1 . \cdot 17$ & YI.YII & $Y 1 . Y \wedge \varepsilon$ & سنة/شهر & السن & 1 \\
\hline$\because 1 \wedge \varepsilon$ & $\cdot \vee \vee \Lambda_{-}$ & $\because .9 \leq$ & $1.7 \ldots$ & 1.701 & سنة/شهر & العمر التدريبى & $r$ \\
\hline \multirow[t]{2}{*}{$.1 \cdot 0$} & $\cdot . V T V=$ & $\because r q r$ & $r .9 \wedge \varepsilon$ & $r .0 r$ & درجة & مقياس الضغوط النفسية & $r$ \\
\hline & & & & & & مقياس السلوك العدوانى & $\varepsilon$ \\
\hline . &. .1992 &. .900 & $1 . v \ldots$ & $1.70 Y$ & لدرجة & التهجم الجسدى & 0 \\
\hline $.01 \leqslant-$ & I.rY &.$r m o$ & $r . .$. & $1 . \wedge 7$. & درجة & العدوان الغير مباشر & 7 \\
\hline$\because \cdot \leqslant 1$ &.$Y 19$ &.. $\mathrm{rqv}$ & $1.9 \ldots$ & 1.217 & درجة & السلوك اللفظى & 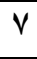 \\
\hline$. .501-$ & $1.1 Y \Lambda_{-}$ &.$r 10$ & $1 . \wedge 7 V$ & $1 . v \leq r$ & درجة & المتوسط العام للمقياس & $\wedge$ \\
\hline
\end{tabular}

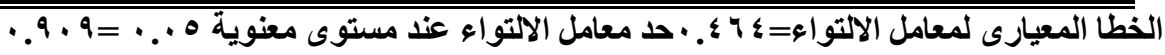

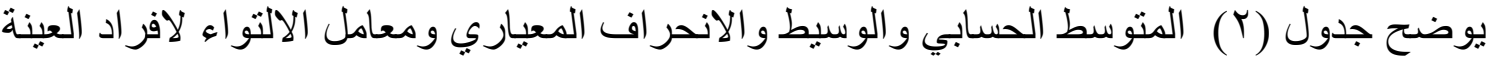

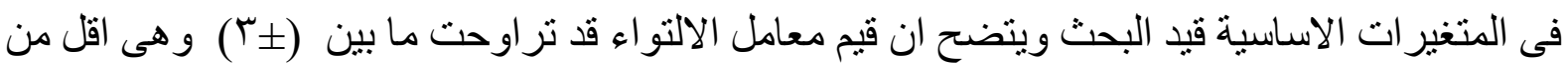

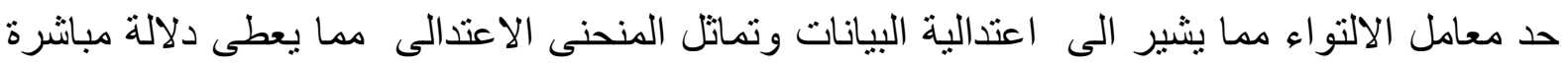

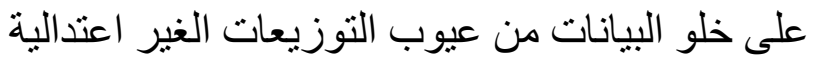


أدوات ووسائل جمع البيانات:

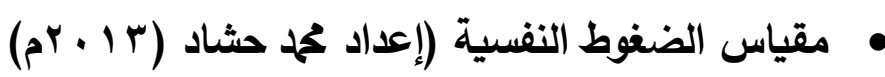

• • مقياس السلوك العدوانى (إعداد الباحث)

حساب المعاملات العلمية لمقياس الضغوط النفسية : (الصدق - الثبات) صدق الاتساق الداخلي للمقياس:

قام الباحث بحساب قيم دعاملات الارتباط بين درجة كل عبارة من عبار اتل الميات المقياس و الدرجة الكلية

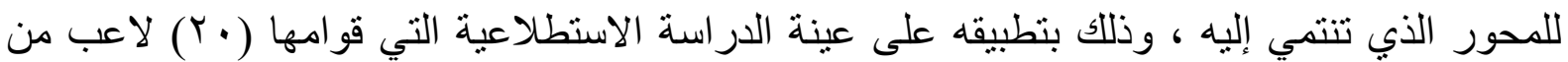

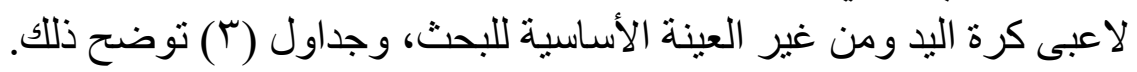

جدول (r) (بار)

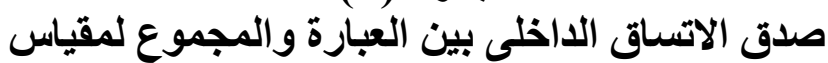

$r \cdot=\dot{0}$

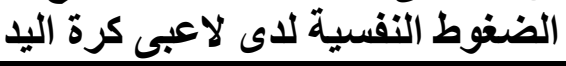

\begin{tabular}{|c|c|c|c|c|c|}
\hline معامل الارتباط & b & معامل الارتباط & b & معامل الارتباط & b \\
\hline$\because 94$. & $\leqslant 0$ & .911 & rT & $\because . \wedge १$ & 1 \\
\hline$\because \wedge \vee \Delta$ & $\leq 7$ & $\because \wedge \wedge \vee$ & $r \varepsilon$ & $\because \wedge r q$ & $r$ \\
\hline$\because \wedge \vee \wedge$ & $\varepsilon V$ & .974 & ro & $\cdot \wedge \Delta r$ & $r$ \\
\hline$\because \wedge \otimes V$ & $\leqslant \wedge$ & $\because \wedge \leqslant \wedge$ & rq & $\cdot . \wedge 4 r$ & $\varepsilon$ \\
\hline$\because \wedge r \varepsilon$ & $\leqslant 9$ & $\because 94$. & $r V$ & $\cdot .9 \leq 1$ & 0 \\
\hline$\cdot .941$ & 0. & .971 & $r \Lambda$ & $\cdot . \wedge r r$ & 7 \\
\hline 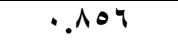 & 01 & $\because \wedge \vee \bullet$ & rq & $\because \wedge \bullet 9$ & $v$ \\
\hline$\cdot .941$ & Or & $\cdot . \wedge 07$ & $r$. & $\because \wedge \wedge \vee$ & $\wedge$ \\
\hline •.Arr & Or & $\because \wedge r q$ & $r$ & .94. & 9 \\
\hline$\because \wedge 0 \leqslant$ & $0 \leqslant$ & $\because 9 Y 1$ & rr & $\because \wedge \leq q$ & 1. \\
\hline .917 & 00 & .974 & $r r$ & •.ヘฯ & 11 \\
\hline$\because \wedge r V$ & 09 & $\because \wedge \wedge \vee$ & $r \varepsilon$ & $\because \wedge \wedge \theta$ & ir \\
\hline$\cdot .9 \cdot 1$ & ov & $\because \wedge \vee q$ & ro & $\because \wedge 9 \vee$ & 14 \\
\hline$\because \wedge \leq V$ & $0 \wedge$ & $\because \vee \wedge \wedge$ & $r 4$ & .991 & $1 \leqslant$ \\
\hline .910 & 09 & $\because \wedge r \wedge$ & $r v$ & $\cdot \wedge \leq r$ & 10 \\
\hline$\cdot . \wedge r r$ & 9. & $\because 9 r$. & $r \Lambda$ & $\because \wedge r \wedge$ & 19 \\
\hline $.91 \leq$ & 71 & $\cdot .117$ & $r q$ & .94 & IV \\
\hline .104 & $4 r$ & $\because$ •r० & $\varepsilon$ & $\because \wedge 0 \leqslant$ & 11 \\
\hline$\because \wedge 9 \wedge$ & 4 & $\because \wedge 79$ & « & $\cdot$. & 19 \\
\hline$\because .140$ & $7 \varepsilon$ & $\because 981$ & $\varepsilon r$ & $\because \wedge \wedge \downarrow$ & $r$. \\
\hline & & $\because \wedge \wedge \neg$ & \& & $\cdot \Lambda \cdot r$ & r) \\
\hline & & $\because .9 .1$ & \& & $\because \wedge \Delta r$ & $r r$ \\
\hline
\end{tabular}

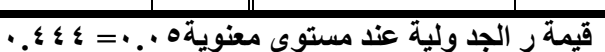

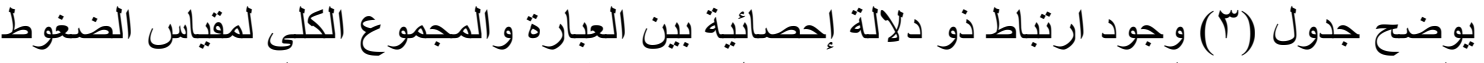

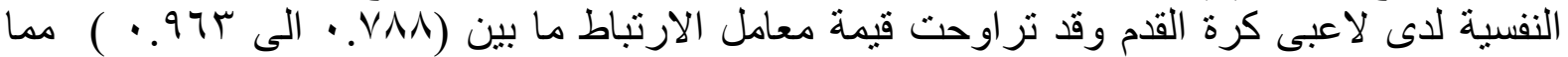
يشير الى صدق الاتساق الداخلي للمقياس وذللك عند مستوى معنوية 0 . .

ثبات مقياس الضغوط النفسية: أـ ثبات المقياس باستخدام التطبيق ثم إعادة تطبيقه 
قام الباحث باستخدام طريقة تطبيق المقياس ثم إعادة تطبيقه مرة أخرى، وبفاصل زمني قدره خمسة

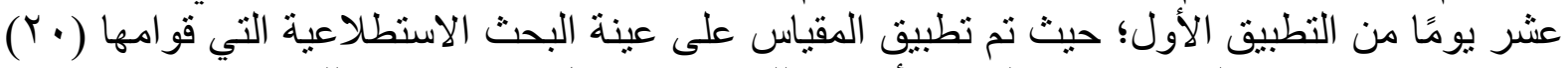

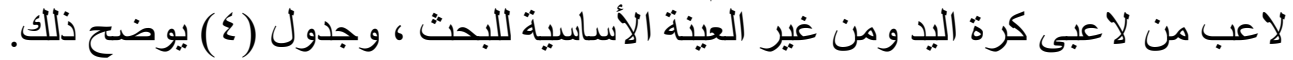

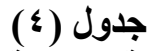

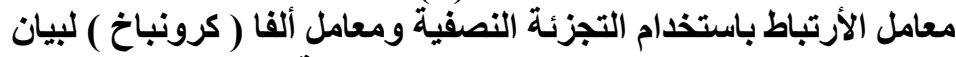

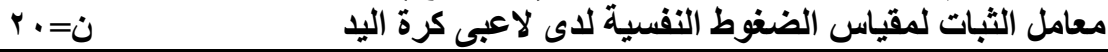

\begin{tabular}{|c|c|c|}
\hline معامل الأرتباط & الاختبار الأحصائى & r \\
\hline $.91 r$ & التجزئة النصفية & 1 \\
\hline$\cdot .9 \cdot 1$ & معامل ألفا ( كرونباخ ) & $r$ \\
\hline
\end{tabular}

يوضح جدول (r) وجود ارتباط ذو دلالة إحصائية بين نصفى عبار ات مقياس الضغوط النفسية

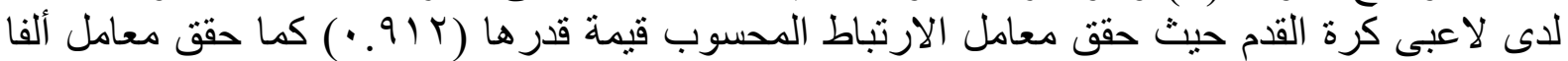

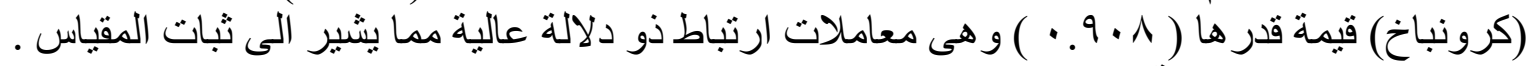

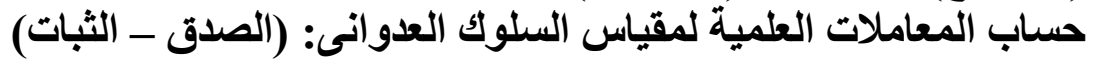
صدق الاتساق الاخلي للمقياس:

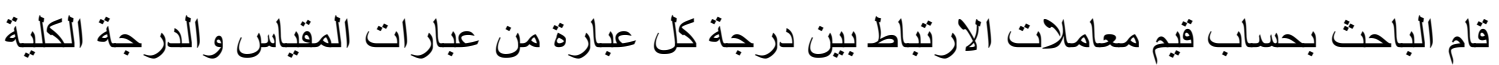

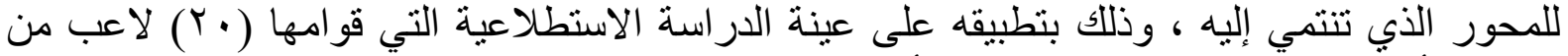

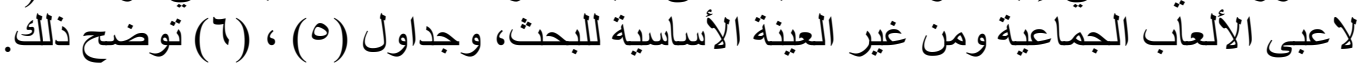

\section{جدول (0)}

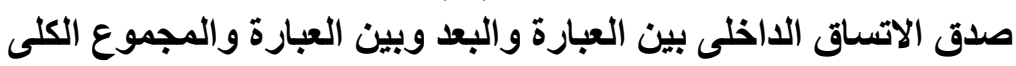

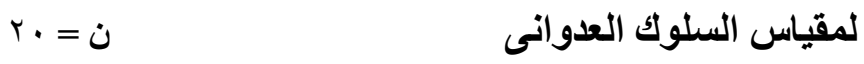

\begin{tabular}{|c|c|c|c|c|c|c|c|c|}
\hline \multicolumn{3}{|c|}{ البعد الثالث } & \multicolumn{3}{|c|}{ البعد الثانى } & \multicolumn{3}{|c|}{ البعد الأول } \\
\hline مع المجموع & البارة مع & $p$ & مع المجموع & العبارة مع البعد & p & مع المجموع & العبارة مع البعد & P \\
\hline$\because$.ヘTV & $\cdot .9 \cdot r$ & 1 & $\because \wedge \wedge \varepsilon$ & $\because 9 r \wedge$ & 1 & $\because \wedge \vee \checkmark$ & $\because \wedge r$ & 1 \\
\hline$\because 91 \leq$ & $\because \wedge \leq 7$ & $r$ & $.9 r V$ & $\because$ • \ & $r$ & $\because \wedge 9 \wedge$ & $\because \wedge \vee r$ & $r$ \\
\hline$\because 940$ & $\cdot \wedge \vee \wedge$ & $r$ & •.ATr & $\because 941$ & $r$ & $\because \wedge \vee \varepsilon$ & $\because 91 V$ & $r$ \\
\hline$\cdot \wedge \leqslant \wedge$ & $\because$ VYo & $\varepsilon$ & $\cdot . \wedge \leq 1$ & $\cdot . \wedge \wedge r$ & $\varepsilon$ & $\because V \wedge r$ & $\because V 1 \leq$ & $\varepsilon$ \\
\hline$\because v \leq r$ & $\because .71 \varepsilon$ & 0 & .910 & $\because \wedge \leq \varepsilon$ & 0 & $\cdot 9 \cdot r$ & $\cdot \Delta r r$ & 0 \\
\hline$\because v r q$ & $\because 1899$ & 7 & $\cdot \wedge \leqslant \wedge$ & $\because \vee \wedge \vee$ & 7 & $\because \wedge Y \varepsilon$ & $\because v 00$ & 7 \\
\hline$\because \vee \wedge 1$ & $\because \wedge Y 1$ & V & $\because V T V$ & .099 & V & $\because \wedge 1 V$ &.$\wedge 9 \mathrm{~V}$ & V \\
\hline$\cdot 9 \cdot \varepsilon$ & $\because \wedge \neg \wedge$ & $\Lambda$ &.$\wedge r \varepsilon$ & $\because \vee \wedge \wedge$ & $\Lambda$ & $\because \wedge 79$ & .919 & $\Lambda$ \\
\hline.$\wedge M r$ & $\because \wedge \wedge \mu$ & 9 &.$\wedge r r$ & .804 & 9 & $\because V Y Y$ &.$\vee \vee 7$ & 9 \\
\hline$\because \wedge r q$ & $\because \vee \wedge \vee$ & 1. & $\because \wedge \vee 1$ & $.9 Y 7$ & 1. & $\because \wedge 9 \leq$ & $\cdot . \wedge \leqslant \varepsilon$ & 1. \\
\hline
\end{tabular}

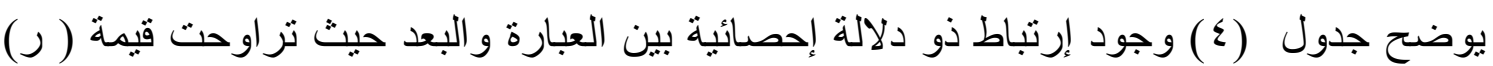

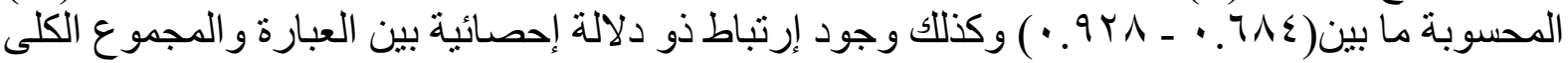

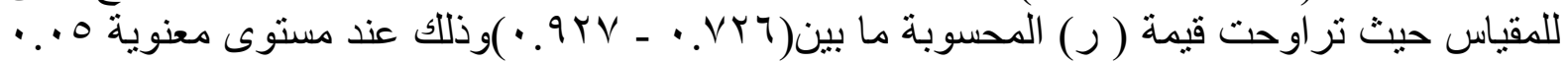
مما يشير إلى صدق الإتساق الداخلى للمقياس قيد البحثة 


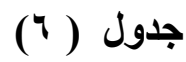

صدق الاتساق الاخلى بين البعد والمجموع الكلى لمقياس السلوك العدوانى

$r \cdot=\dot{0}$

\begin{tabular}{c||c||c}
\hline \hline قئ||c|| & 1 \\
\hline \hline
\end{tabular}

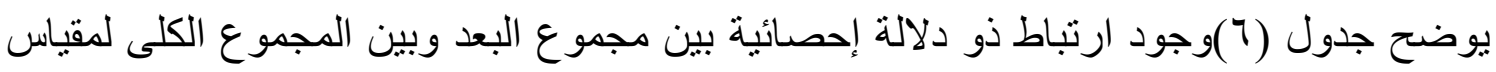

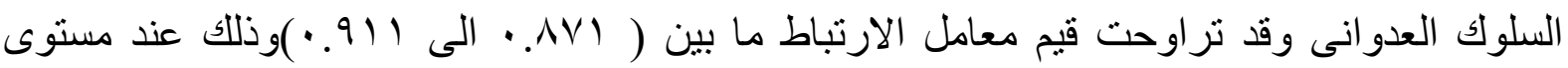

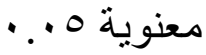

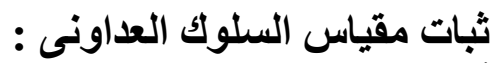
أـ ثبات المقياس باستخدام التطبيق ثم إعادة تطبيقه

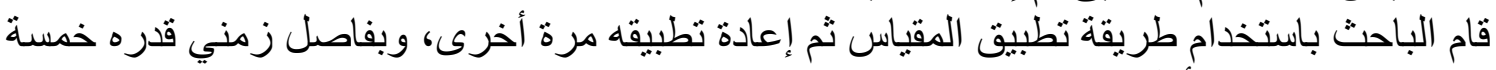

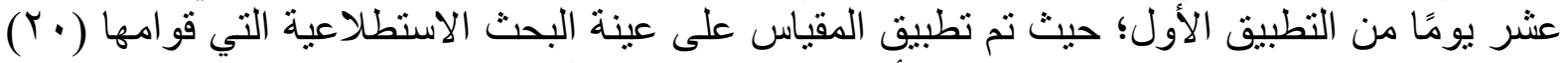

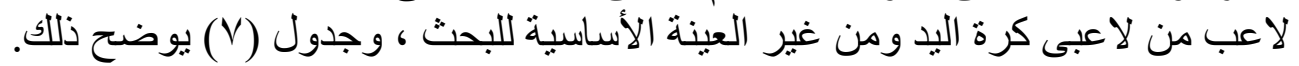

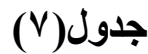
التجزئة النصفية ومعامل الفا لبيان معامل الثبات لمقياس

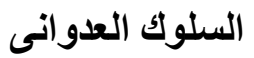

$r \cdot=\dot{u}$

\begin{tabular}{|c|c|c|c|c|}
\hline معامل الفا & صفية & اختبار التجزئة & & \\
\hline Deleted Cronbach's Alpha if Item & 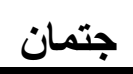 & سبيرمان -براون - & & ? \\
\hline .1991 & $\because \vee \vee \wedge I$ &.$\vee \vee 9 T$ & التهجم الجسدى & 1 \\
\hline. $\mathrm{VAr}$ & $\because \wedge \wedge \uparrow$ & .1990 & العدوان الغير مباشر & $r$ \\
\hline.$\vee \vee q \varepsilon$ & $\because \vee 9 \varepsilon$ & $\because \vee \wedge \wedge$ & السلوك اللفظى & $r$ \\
\hline$\because 199$ & $\cdot \wedge) \leqslant$ &.$\wedge r r$ & الارجة الكلية & \\
\hline
\end{tabular}

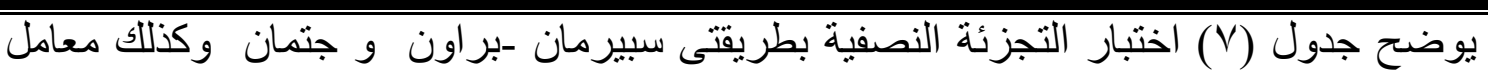

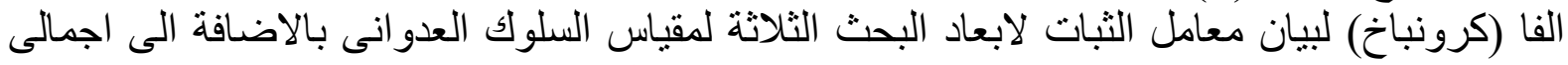

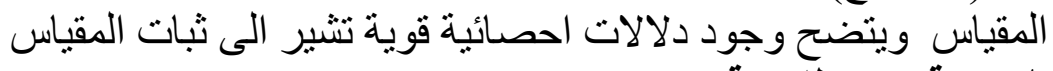
الار اسة الاستطلاعية

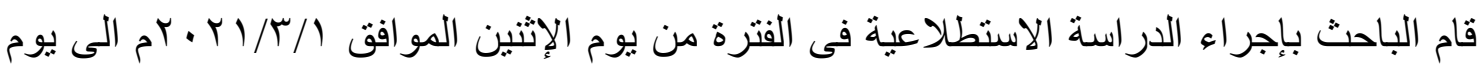

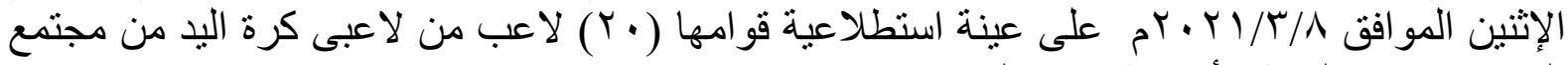

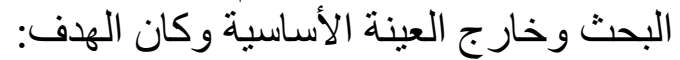

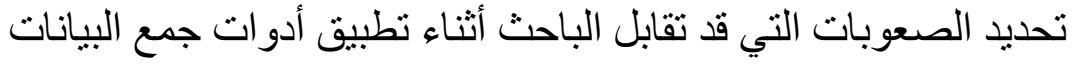

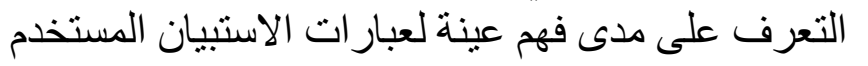
حساب المعاملات العلمية (الصدق - الثبات) لاستمارة الاستبيان قبد البحث 


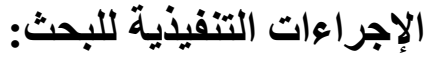

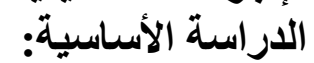

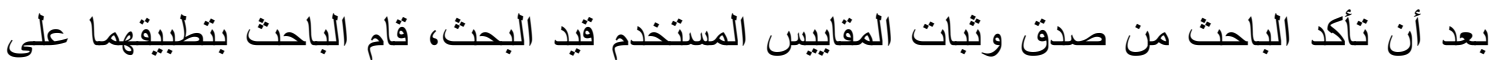

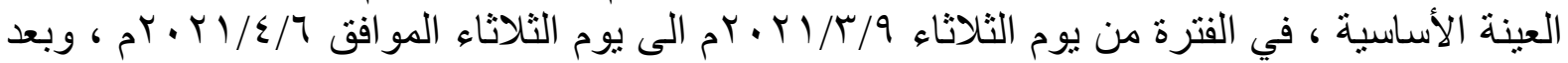

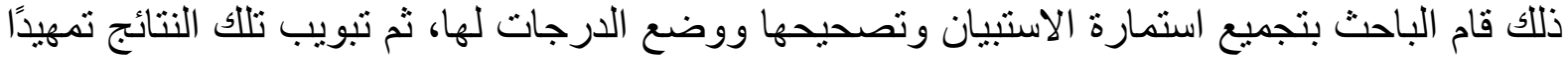

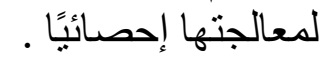
المعالجات الإحصائية

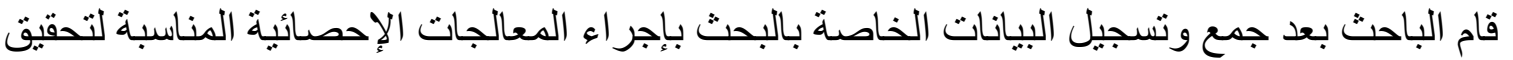

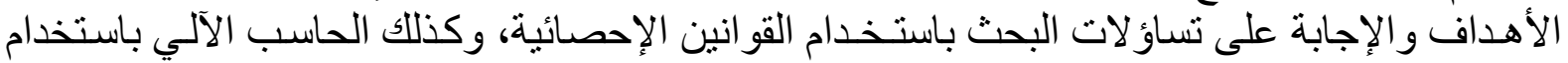
البرنامج الإحصائي "SPSS" (الحزمة الإحصائية للعلوم الإجتماعية) ، وتم حساب مالئية وكائي:

Mean.

المتوسط الحسابي.

Standard Deviation

الانحر اف المعياري

Correlation (person) معامل الارتباط البسيط (بيرسون)

Cronbachs Alpha

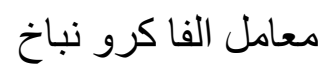

Percentage

النسبة المئوية

Relative importance الأهمية النسبية

Variation coefficient معامل الاختلاف 
جدول (^)

عرض ومناقشة النتائج

تحليل عبارات مقياس الضغوط النفسية لدى لاعبى كرة اليا

\begin{tabular}{|c|c|c|c|c|}
\hline الاهمية النسبية & معامل الاختلاف & الانحراف المعيارى & المستوسطى & رقم العبارة \\
\hline TV.Y.. & וT.MVI & 1. ros & ק.r. & 1 \\
\hline $70.7 \ldots$ & ro.VVY & $1.1 \mathrm{Vr}$ & r.YA. & $r$ \\
\hline $07 . .$. & $\varepsilon \varepsilon .94 q$ & 1.101 & r.A.. & $r$ \\
\hline or.A... & \&I.YTV & I.YYI & T.7ะ. & $\varepsilon$ \\
\hline $09 . Y .$. & $\Sigma 0 . Y .$. & I.rM & r.97. & 0 \\
\hline $07 . .$. & $\varepsilon \varepsilon .94 q$ & $1 . r 01$ & r.A.. & 7 \\
\hline$\neg . \wedge \ldots$ & $\varepsilon 0 .+r T$ & 1.479 & r... & $V$ \\
\hline $07 . .$. & $\varepsilon V . Y \leq T$ & אזr. & Y.A.. & $\Lambda$ \\
\hline 71.7. & $\varepsilon Y . \wedge 7 q$ & I.r. & $r . \wedge$. & 9 \\
\hline $7 \cdot \wedge \ldots$ & $\varepsilon \wedge . \wedge 70$ & $1 . \leqslant \wedge 0$ & $r . \varepsilon$. & 1. \\
\hline TV.Y.. & $\varepsilon 1.9 \wedge \varepsilon$ & 1.211 & . דז.ז. & 11 \\
\hline $07 . .$. & $\leqslant 9 . \leqslant \leqslant \leqslant$ & $1 . r \wedge \varepsilon$ & r.A.. & IT \\
\hline$V \cdot . \varepsilon \ldots$ & ro.A7. & $1 . Y 7 Y$ & r.or. & 11 \\
\hline TV.Y.. & $\varepsilon \cdot .1 \wedge \wedge$ & $1 . r 0$. & r.ז. & $1 \varepsilon$ \\
\hline $71.7 \ldots$ & $\varepsilon \cdot . \vee \neg \Lambda$ & 1.107 & $r . \wedge$. & 10 \\
\hline$\varepsilon r . Y$. & $01 . Y .7$ & 1.1 .7 & T.17. & 17 \\
\hline $71.7 \ldots$ & $\sum r . \wedge \wedge 1$ & 1.ror & $r . \wedge$. & IV \\
\hline $71.7 \ldots$ & $\sum r . \wedge 7 q$ & I.r. & $r . \wedge$. & 11 \\
\hline $7 \varepsilon \ldots$ & 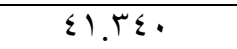 & אוזr & r.Y.. & 19 \\
\hline $09.1 \ldots$ & $\varepsilon 1.940$ & $1 . Y \leq 1$ & Y.97. & $r$. \\
\hline$\varepsilon \varepsilon . \wedge \ldots$ & $\varepsilon \wedge . \vee \ldots$ & 1.99 & T.Y. & YI \\
\hline o^.乏.. & ะ9. ror & $1 . \leqslant \leqslant 1$ & r.qr. & rr \\
\hline$\neg \leqslant . \wedge \ldots$ & rV.PV & $1 . r \ldots$ & T.Y. & $r T$ \\
\hline Oᄉ.乏.. & $\varepsilon \wedge . \% 01$ & $1 . \Sigma 1 T$ & r.qY. & $r \varepsilon$ \\
\hline$\neg . \wedge \ldots$ & $\varepsilon V .9 T r$ & $1 . \leqslant 0 \mathrm{~V}$ & r... & ro \\
\hline Tr. $\varepsilon$ & $50.7 Y q$ & $1 . \leqslant Y \varepsilon$ & r.Ir. & $r T$ \\
\hline $0 . \Sigma \ldots$ & $\varepsilon \wedge . \vee \neg T$ & $1 . r Y q$ & r.OY. & TV \\
\hline $00 . Y .$. & $01.04 \wedge$ & $1 . \Sigma Y Y$ & Y.VY. & $r \Lambda$ \\
\hline TY.E. & $E Y . V Y Y$ & I.rT & r.IT. & 19 \\
\hline $09.1 .$. & $\varepsilon q . Y Y q$ & $1 . \leqslant 0 V$ & r.97. & $r$. \\
\hline $09.1 .$. & $\varepsilon r . \cdot \varepsilon \varepsilon$ & $1 . Y V \varepsilon$ & Y.97. & 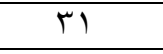 \\
\hline$\neg \varepsilon . \wedge \ldots$ & $\varepsilon . .1 T r$ & I.r... & r.Y & rT \\
\hline$\neg . \wedge$. & $\varepsilon \varepsilon .1$ & 1. IT & $r . \varepsilon$. & r \\
\hline $77 . \varepsilon \ldots$ & $\leqslant 1 . \leqslant \leqslant 0$ & $1 . r V T$ & r.r. & $r \varepsilon$ \\
\hline $7 \varepsilon \ldots$ & $\varepsilon Y$ IIT & $1 . r 0 \varepsilon$ & r.Y.. & ro \\
\hline$\neg \varepsilon . \wedge \ldots$ & $10.9 \leqslant 9$ & 1.170 & $r . r \leq$. & ru \\
\hline $09.1 .$. & $\varepsilon r . \cdot \varepsilon \varepsilon$ & $1 . Y V \varepsilon$ & Y.97. & rV \\
\hline$\neg . \wedge \ldots$ & $\leqslant 7 .+1 T$ & 1.199 & $r . \varepsilon$. & rᄉ \\
\hline or.7.. & $\{q . \cdot T)$ & $1 . M 1 \varepsilon$ & T.71. & rq \\
\hline$V I . Y$. & r7.99r & .971 & 1.07. & $\varepsilon$. \\
\hline
\end{tabular}




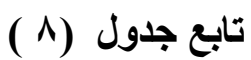

تحليل عبارات مقياس الضغوط النفسية لدى لاعبى كرة اليا

\begin{tabular}{|c|c|c|c|c|}
\hline الاهمية النسبية & معامل الاختلاف & الانحراف المعيارى & الحستوسطى & رقم العبارة \\
\hline $7 \leq \ldots$ & M.Yo. & $1 \ldots$ & r.Y.. & $\varepsilon 1$ \\
\hline TV.Y.. & rq. r०q & 1.119 & . דז.ז. & $\varepsilon r$ \\
\hline $71.7 \ldots$ & r.Y.r & 1.110 & $r . \wedge$. & $\varepsilon r$ \\
\hline $07 . .$. & $01.0 \leqslant 9$ & $1 . \leqslant \leqslant T$ & ঙ.^.. & $\varepsilon \varepsilon$ \\
\hline ov.7.. & $\varepsilon 0.1 \wedge r$ & $1 . r \cdot 1$ & 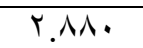 & $\varepsilon 0$ \\
\hline o^.乏.. & rq. $\leqslant \leqslant 7$ & 1.104 & r.qY. & $\sum \uparrow$ \\
\hline Tr... & r.VAᄉ & 1.71 & r.17. & $\varepsilon V$ \\
\hline TY.E. & $\varepsilon I . V \cdot \Lambda$ & $1 . r \cdot 1$ & r.IY. & $\varepsilon \wedge$ \\
\hline 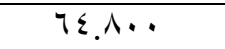 & 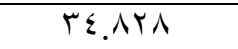 & $1.1 Y \wedge$ & T.Y & $\varepsilon 9$ \\
\hline $70.7 \ldots$ & TO.VVY & $1.1 \mathrm{VT}$ & r.YA. & 0. \\
\hline 71.7. & rq. TVT & I.YYY & $r . \wedge$. & 01 \\
\hline $07 . \wedge \ldots$ & $\varepsilon r . q \mu r$ & $1 . r \leqslant \Lambda$ & 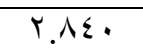 & Or \\
\hline $7 \varepsilon . .$. & rA.rVT & I.YYO & r.Y.. & or \\
\hline ov.7.. & $\varepsilon \nearrow . Y \wedge Y$ & זrr. & 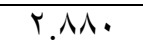 & $0\}$ \\
\hline$\vee Y . \wedge \ldots$ & Tะ.ร7. & $1 . Y 0 \leqslant$ & T.7ะ. & 00 \\
\hline TV.Y.. & r. r & I.YYI & ק.ז. & 07 \\
\hline$\varepsilon\rceil . \leqslant \ldots$ & צr.A & $1 . r \leqslant 9$ & r.r. & OV \\
\hline $71.7 \ldots$ & rᄉ.00r & $1.1 \wedge \mathrm{V}$ & $r . \wedge$. & 01 \\
\hline$\neg . \wedge \ldots$ & $\varepsilon r .9 \vee \leqslant$ & $1 . r .7$ & $r . \varepsilon$. & 09 \\
\hline $70.7 \ldots$ & q ד & $1 . r \cdot \Lambda$ & r.YA. & 7. \\
\hline TV.Y.. & \&1.97 & $1 . \mu N$ & ק.ז. & 71 \\
\hline$V \cdot . \varepsilon \ldots$ & rะ.q1. & $1 . Y Y q$ & r.or. & $7 r$ \\
\hline$\neg \wedge . \wedge \ldots$ & Y9.17V & $\ldots r$ & r. $\leqslant \varepsilon$. & $7 \pi$ \\
\hline $07 . \wedge \ldots$ & rV.090 & 1.71 & r.A乏. & $7 \varepsilon$ \\
\hline $71 . . \varepsilon$. & $9.7 \ldots$ & rq & $r .0 r$ & المتوسط العام للبعد \\
\hline
\end{tabular}

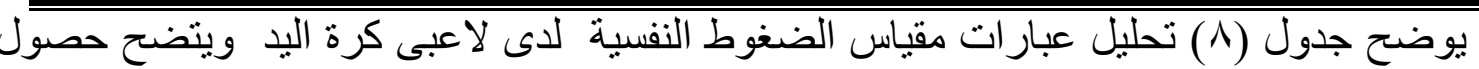

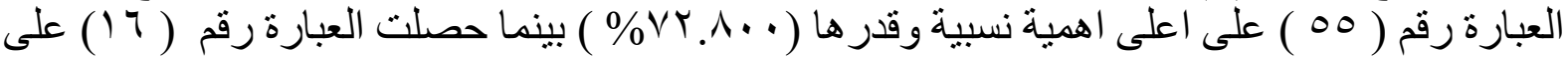

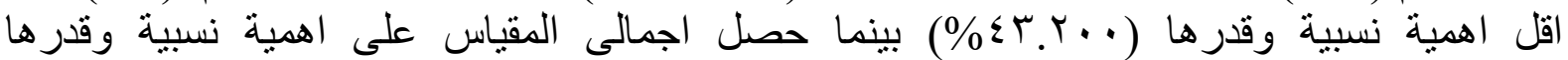




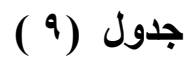

تحليل عبارات البعد الاول الخاص بالتهجم الجسدى فى مقياس السلوك العدوانى

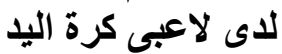

\begin{tabular}{|c|c|c|c|c|}
\hline الاهمية النسبية & معامل الاختلاف & الاتحراف المعيارى & المتوسط الحسابى & رقم العبارة \\
\hline TY.TTV & $r \Lambda .7 \cdot r$ &.$V Y T$ & $1 . \wedge \wedge$. & 1 \\
\hline$\varepsilon 7.77 \mathrm{~V}$ & $\leqslant 7.1 \cdot V$ & $.7 \leqslant 0$ & $1 . \varepsilon \cdots$ & $r$ \\
\hline$\varepsilon Y .7 T V$ & or. .9AV & $.7 \vee \wedge$ & $1 . r \wedge$. & $r$ \\
\hline$V Y . .$. & $\varepsilon r .7 \vee\urcorner$ & $\cdot .9 \leq r$ & 4.17. & $\varepsilon$ \\
\hline מדr.ror & EV.VTo & $\because \vee \backslash \varepsilon$ & $1.7 \ldots$ & 0 \\
\hline $7 . .$. & $0 . .110$ & .911 & $1 . \wedge \ldots$ & 7 \\
\hline Eq.TH & 19.091 & $.0 \wedge 7$ & $1 . \leqslant \wedge$. & 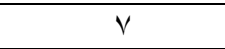 \\
\hline TY. TTV & \&q.TYA & $.9 Y V$ & $1 . \wedge \wedge$. & $\Lambda$ \\
\hline TrMT & M..人E & $.0 \mathrm{VV}$ & $1.7 \ldots$ & 9 \\
\hline$\Sigma \wedge .$. & $\{q . \leqslant \Gamma$ &.$V \backslash Y$ & $1 . \leqslant \varepsilon$. & 1. \\
\hline $00.7 \mathrm{~V}$ & 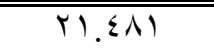 & .100 & 1.704 & المتوسط العام للبعد \\
\hline
\end{tabular}

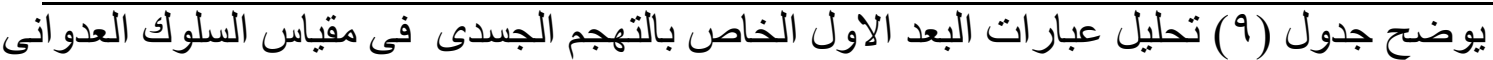

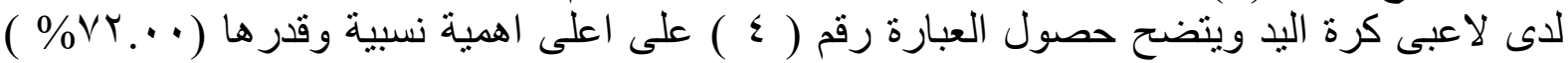

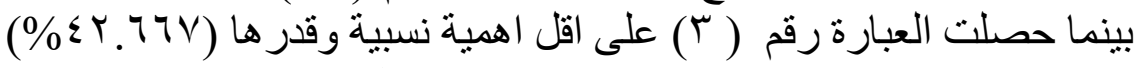
جدول (1.

تحليل عبارات البعد الثانى الخاص بالعدوان الغير مباشر فى مقياس السلوك العدوانى

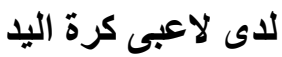

\begin{tabular}{|c|c|c|c|c|}
\hline الاهمية النسبية & معامل الاختلاف & الانحر اف المعيارى & المتوسط الحسابى & رقم العبارة \\
\hline VE. ITV & ET.Y人T & $.9 V$. & T.Y & 1 \\
\hline $9 \varepsilon .77 V$ & 19.599 & $.00 \leqslant$ & 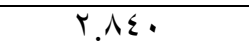 & $r$ \\
\hline \&Y. ไTV & EY.YIT & $.0 \leqslant Y$ & I. Yᄉ. & $r$ \\
\hline $0 \leqslant .77 V$ & 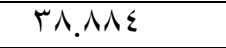 & . & $1.7 \varepsilon$. & $\varepsilon$ \\
\hline $07 . .$. & $\varepsilon V . V \leqslant r$ & $\cdot \Lambda \cdot r$ & $1.7 \wedge$. & 0 \\
\hline חוזי.10 & YY.VVV & $.0 \wedge T$ & Y.07. & 7 \\
\hline $7 \cdot \ldots$ & rq.YAE & $\because V \cdot V$ & $1 . \wedge \ldots$ & 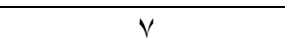 \\
\hline בO & T. Tr & $\because \leqslant 9$. & $1 . \%$. & $\Lambda$ \\
\hline TY.7TV & $r \wedge .7 \cdot r$ &.$V Y T$ & $1 . \wedge \wedge$. & 9 \\
\hline$\varepsilon \varepsilon \ldots$ & OY.Y.E & .79 & I.r. & 1. \\
\hline Tr... & אוr. 11 & ס סחז. & $1 . \wedge 7$. & المتوسط العام للبعد \\
\hline
\end{tabular}

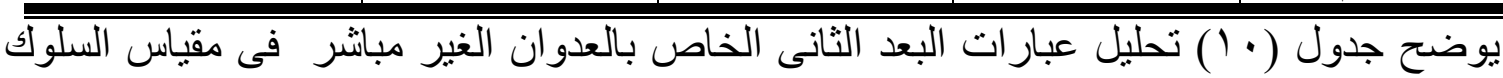

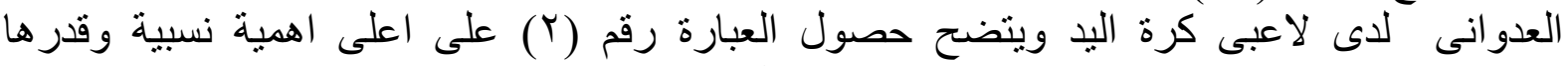

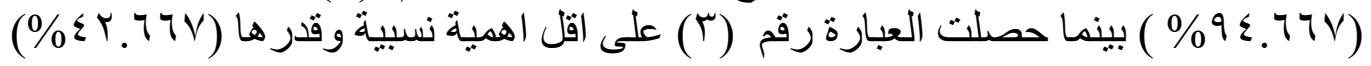


جدول (11) - (11)

تحليل عبارات البعد الثالث الخاص بالسلوك اللفظى فى مقياس السلوك العدوانى

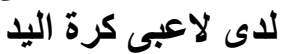

\begin{tabular}{|c|c|c|c|c|}
\hline الاهمية النسبية & معامل الاختلاف & الاتحراف المعيارى & المتوسط الحسابى & رقم العبارة \\
\hline $0 \varepsilon .77 \mathrm{~V}$ & $\varepsilon 7.1 \mathrm{~V}$ & $\because \mathrm{VOV}$ & $1.7 \varepsilon$ & 1 \\
\hline $01.77 \mathrm{~V}$ & $\{9.977$ & $\because \wedge \vee q$ & 1.87. & $r$ \\
\hline $07 . .$. & $0 . . V \leqslant 1$ & $\because \wedge 0 Y$ & 1.71 & $r$ \\
\hline $7 \leq .$. & $\varepsilon \varepsilon .9 .0$ & $\cdot . \wedge 7 r$ & $1.9 Y$. & $\varepsilon$ \\
\hline $0 \leqslant .77 V$ & Or.sor &.$\wedge 7$. & $1.7 \varepsilon$. & 0 \\
\hline 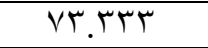 & rV.IIr &.$\wedge 17$ & r. r.. & 7 \\
\hline EO.MTK & $00.7 \times 7$ & $\because \mathrm{VOV}$ & 1.1. & V \\
\hline$\varepsilon \wedge .$. & $\varepsilon \cdot . \varepsilon q \mu$ & $.0 \wedge \mu$ & $1 . \leqslant \varepsilon \cdot$ & $\Lambda$ \\
\hline OV.MT & $\varepsilon \wedge .9 \wedge 9$ & $\cdot . \wedge \varepsilon r$ & I.VY. & 9 \\
\hline $7 . \ldots$ & $\sum Y . \leq M$ &.$V 7 \varepsilon$ & $1 . \wedge \ldots$ & 1. \\
\hline OV.Y.. & rr.l. &.$r q V$ & 1.917 & المتوسط العام للبعد \\
\hline
\end{tabular}

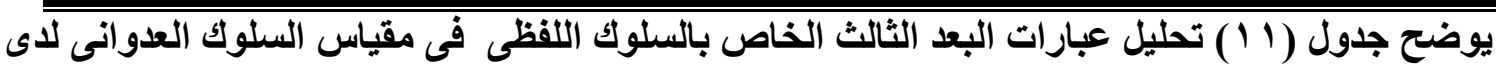

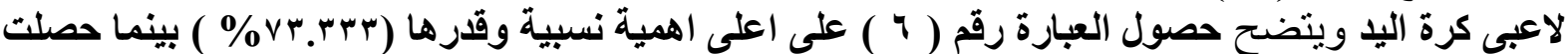

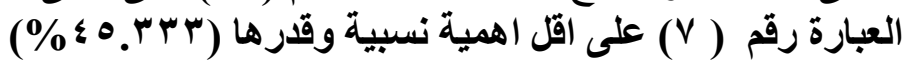

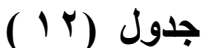

تحليل ابعاد واجمالى مقياس بالسلوك العدوانى لاى لاعبى كرة اليا

\begin{tabular}{|c|c|c|c|c|c|}
\hline الاهمية & الاختلاف معامل & الانحر اف & الحستوسط & ابعاد المقياس & 5 \\
\hline $00.7 \mathrm{~V}$ & YI. $\{\lambda !$ &. .100 & 1.704 & التهجم الجسدى & 1 \\
\hline Tr.... & 11.04 & ס Tr. & $1 . \wedge 7$. & العدوان الغير مباشر & r \\
\hline OV.Y.. & $r$ r.I. &.$r q V$ & 1.217 & السلوك اللفظى & r \\
\hline 01.91 & 11.979 &. .10 & $1 . V \leqslant r$ & المتوسط العام المقياس & \\
\hline
\end{tabular}

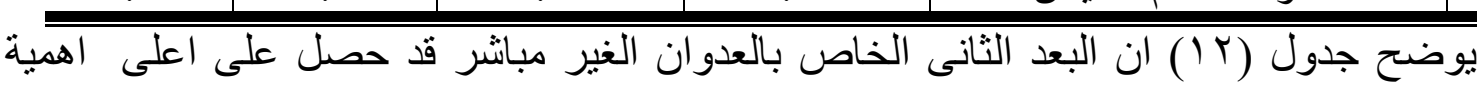

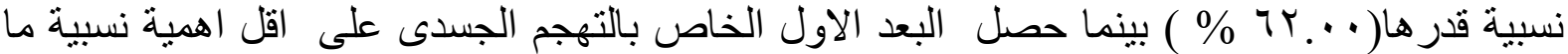

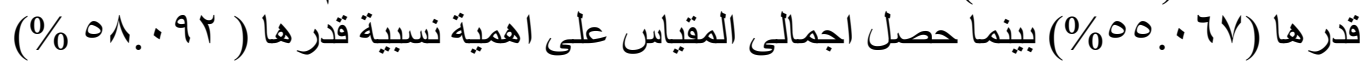

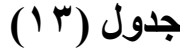

معامل الارتباط لبيان العلاقة بين الضغوط النفسية والسلوك العدوانى لاى لاعبى كرة اليد $r \bullet=\dot{0}$

\begin{tabular}{|c|c|c|c|c|}
\hline \multicolumn{4}{|c|}{ السلوك العدو انى } & \multirow{2}{*}{ المتغير ات } \\
\hline الاجمالى & السلوك اللفظى & العدو ان الغير مباشر & التهجم الجسدى & \\
\hline$* .109$ & $* . \wedge \vee 0$ & $* . \Lambda \mu V$ & $* . \wedge \leq 7$ & الضغوط النفسية \\
\hline
\end{tabular}

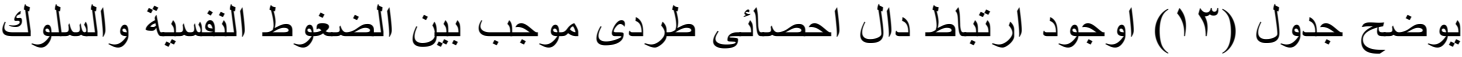

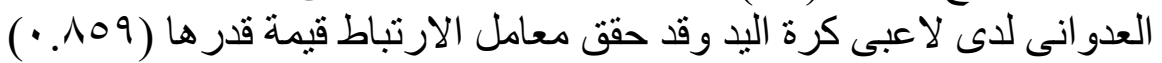


جدول (^) تحليل عبار ات مقياس الضغوط النفسية لدى لاعبى كرة اليد ويتضح حصول العبارة

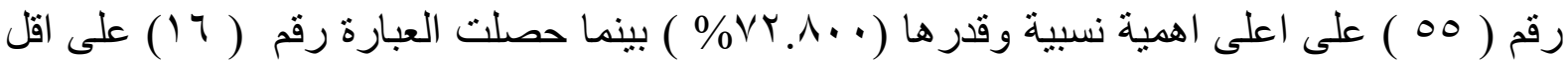

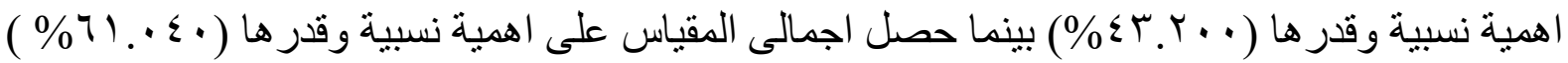

يرجع الباحث ذلك الى أن مستوى الضغوط النفسية يؤثر بصورة سلبية عليهم مثل تبديد الطاقة البدنية لهم و الحرمان من الإستمتاع بممارسة الرياضة والفوز فى المنافسة ، كما انها تؤدى الى نقص الدافعية لديهج و الاهتمام بالإنجاز كما أنها تسبب صر اع داخلى . وهذا يتفق مع نتائج در اسة إبراهيم صبرى (· • • ( م) (1) إلى ان من عوامل الضغوط التى يتعرض لها اللاعبين هى تعرض لاعبي الفرق الأولى الأساسية بالقسم الأول والثاني لضغوط نفسية تختلف شدتها وفق المتغيرات النفسية بأبعادها " ضغط الجمهور، والمكافآت ، والعلاقة بالمدرب ، وضغط الحكام، و الإمكانات، وضغط الإصابة ، وضغط الإعلام، وضغط الإدارة " زادت شدتها وشدة القلق لاى اللاعبين، كلما ارتفعت السلبية لضغوط التدريب، وعدم وجود فترات راحة مناسبة تسمح للرياضي باستعادة الثفاء و استجماع القوى . ويرى الباحث أن الضغط الذى يعانى منه اللاعبين قبل وأثناء المنافسة الرياضية ويرتكبون أخطاء ليست سمة من سمات سلوكهم المعتاد وذلك بسبب الجمهور الذى يثير اللاعبين أثناء المنافسة وأنهر يتعرضون لضغوط أكبر من المعتادة بالإضافة إلى حاجتهم للنجاح و الأداء الأمثل.

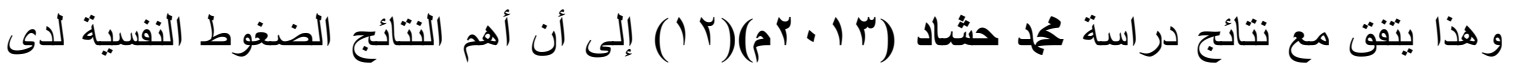
اللاعبين تشتمل على 7 محاور وهى ضغوط تتعلق بقلق المنافسة (قبل - أثناء - بعد) ، توجد فروق دالة إحصائياً بين الناتشئين فى مصادر الضغوط النفسية وذلك لإختلاف العمر الزمنى ـ العمر التدريبى مدى تحقق النتائج

كما أن قرب مو عد المنافسة يؤثر على حياة اللاعبين بصورة سلبية مما يجعلهم أكثر عرضة للقلق الثديد و التوتر وذللك لان المنافسة ترتبط بمجمو عة من المتغير ات التي قد تزيد في حدة انفعالات اللاعب ومن ثم قد تحيده عن المستوى الأمثل له من التوتر والاستثارة . ويرجع الباحث الضغوط النفية لدى اللاعبين وذلك لعدم قدرتهم على التوازن بين مو اعيد تدريبهر ومو اعيد الدر اسة مما يؤدى إلى وجود بعض حالات الفثل و تعزى أسر اللاعبين هذه النتيجة إلى أن كرة اليد تضيع الوقت الذى يمكن إستغلاله فى الدراسة . ويرى الباحث هذه الضغوط زيادة جرعات التدريب ولا توجد راحات طويلة بين التدريب والآخر مما يؤثر على اللاعب و عدم إستجماع طاقاتهم بعد التدريب . 
و عدم تخطيط الددرب الجيد يؤدى إلى إصابة أكثر من لاعب مما يؤثر على اللاعبين الآخرين

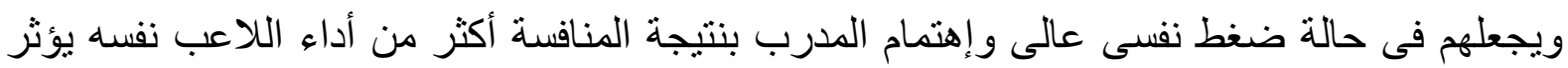
على اللاعبين بصورة سلبيه . و المشكلات الأسرية أحد مصادر الضغوط النفسية للاعب، والتي منها المشكلات العائلية داخل الأسرة و التي تسبب الاضطر ابات النفسية داخل أسرة اللاعب ، الاستثارة الانفعالية العالية لأفر اد الأسرة أثناء المنافسة تصل لدرجة السلوك غير المرغوب فيه ، وهذا يمثل نوع من الضغط النفسي". وزيادة حمل التدريب عن قدرة تحمل اللاعب، وتخطي حدود التعب البدني و العضلي العادي إلى في لإني درجة الإعياء ، والارتفاع المفاجيء للحمل التدريبي لدرجة الإجهاد، وعدم إعطاء الراحة الكافية لاستعادة الثنفاء، والاستمر ار في تنفيذ أحمال بدنية عالية لفترات طويلة ، كل ذللك قد يؤدي إلى المزيد كم

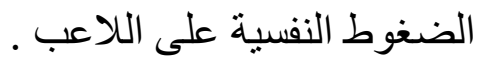
يوضح جدول (9) تحليل عبار ات البعد الاول الخاص بالتهجم الجسدى فى مقياس السلوك العدوانى لاى لاعبى كرة اليد ويتضح حصول العبارة رقم ( ؛ ) على اعلى اهمية نسبية وقدرها ( ...VY\% )

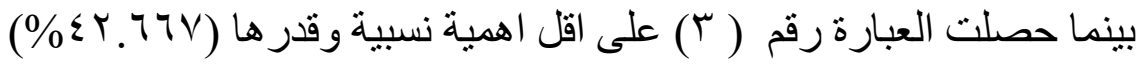
يوضح جدول (• () تحليل عبار ات البعد الثانى الخاص بالعدوان الغير مبانثر فى مقياس السلوك العدوانى لدى لاعبى كرة اليد ويتضح حصول العبارة رقم (r) على اعلى اهمية نسبية وقدرها

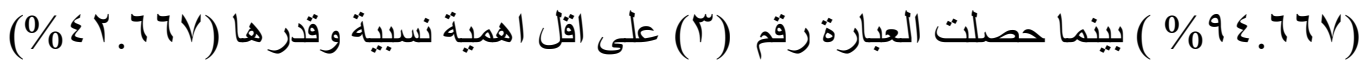
يوضح جدول (1') تحليل عبارات البعد الثالث الخاص بالسلوك اللفظى فى مقياس السلوك العدوانى لدى لاعبى كرة اليد ويتضح حصول العبارة رقم ( 1 ) ) على اعلى اهية نسبية وقدرها

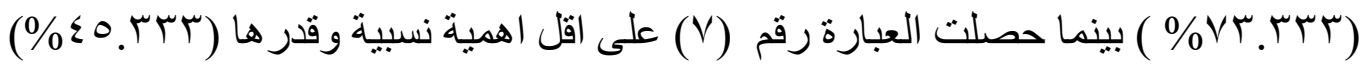
يوضح جدول (Y) ( ان البعد الثانى الخاص بالعدوان الغير مبانر قد حصل على اعلى اهمية

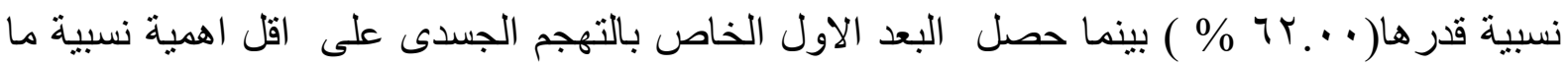

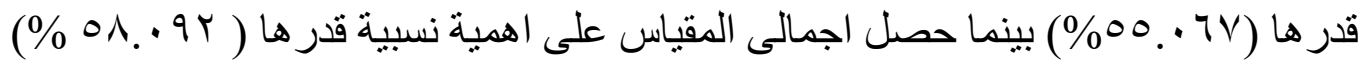

برجع الباحث هذا الى غالباً ما تأتي المثير ات من السلوك العدو اني للاعبين أنفسهم، و عادة هو نفس النوع من المثيرات التي تستدعي غضب للاعبين الفريق المنافس وغضب الجمهور، حيث يوجد أثنياء معينة مثل الزجاجات وعلب العصائر الفارغة ومكعبات الثلج للمشروبات الباردة، و أثنياء أخرى كإثار ات غير نربوية تعمل كعصا مثيرة ومنبهة لمثيرات الغضب و العنف الرياضي، حيث تستخدم كأداة

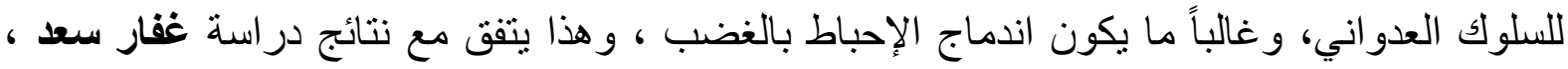


ويثير الباحث أن الحركات التي تأتي من جمهور المشاهدين، مثل حركات موجات البحر أو

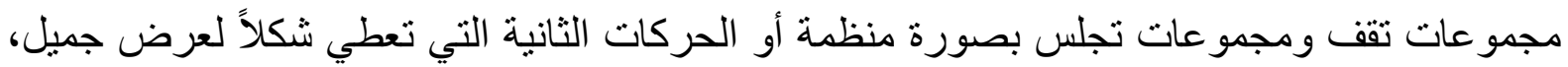

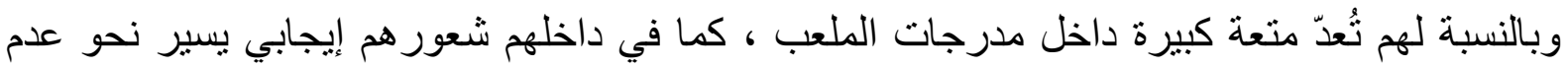
إيذاء الآخرين وخرق حقوقهم التي وفرها القانون لهم ، أما إذا كانت الاستجابة للإحباط نوع من إثارة الغضب لدى جمهور المشاهدين بحيث تؤدي إلى حدوث إصابة بالجسم، حيث أن مثل هذا السلوك غالباً ما يتضمن النية للإيذاء و الإصابة أو تجاهل حقوق و احتر ام الآخرين. يرجع الباحث هذا الى السلوك الذي يوقعه الفرد على شخص أو شيء ما ، دون قصد أو تعدد مترصد، مثل الجمهور الذي يتسم بحركة زائدة ، فيمكن أن يؤذي الآخرين دون علم منه ، من هنا

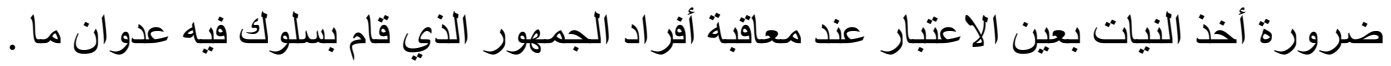
كما يرجع الباحث أيضا هذا اللسوك العدوانى اللفظى الى غياب الروح الرياضية السامية، وكنلك

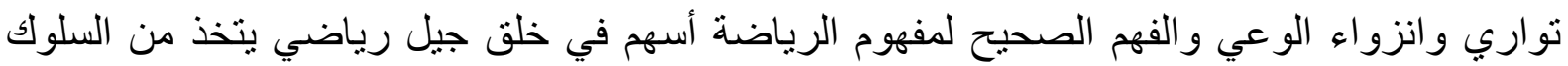

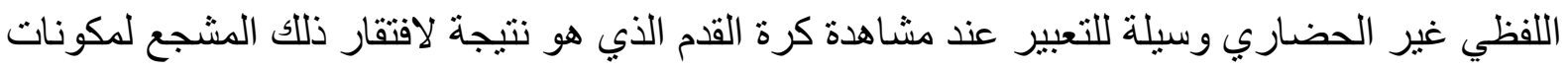
الروح الرياضية التي تنادي بضرورة تقبل النتيجة، واحترام المنافس، و الاعتر اف بتفوقه، واحترام حتى أعضاء فريقه عند تعرضهم للخسارة، وضبط النفس، وتحول تفضيل فريقه إلى حقد على الطرف الطف المنافس، وصار التتجيع في مفهومه هيجاناً. ولذا نجده عوضاً عن الامتنال لتلك القيم يقوم أثناء سير

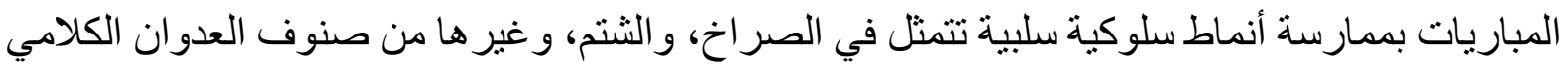
ربما اعتقاداً منه أنه بحكم أنه ضمن حشد جماهيري فهو في حل من الضوابط الرياضية التي تدعو لها

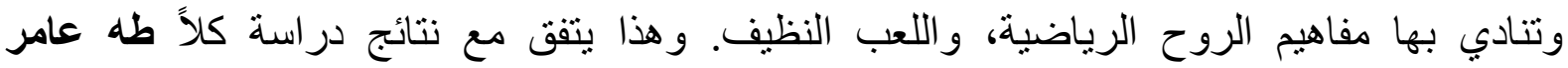

$(7)\left(P^{r}+19\right)$

يوضح جدول (r ا) اوجود ارتباط دال احصائى طردى موجب بين الضغوط النفسية والسلوك

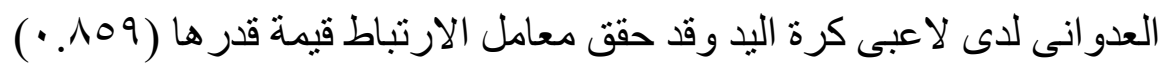

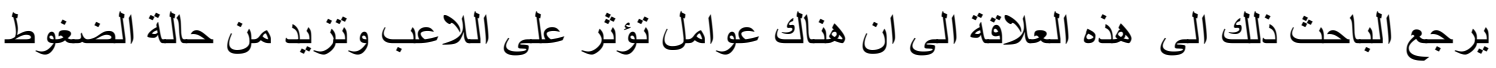
النفسية أي نوع من انواع الرياضة شروطا او منطلبات خاصة فيما يخص بناء وتكوين شخصية

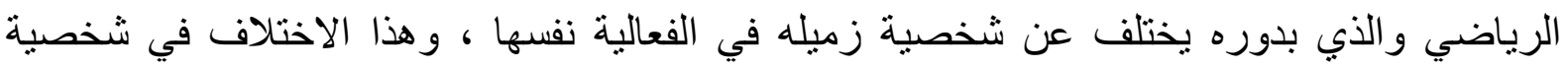

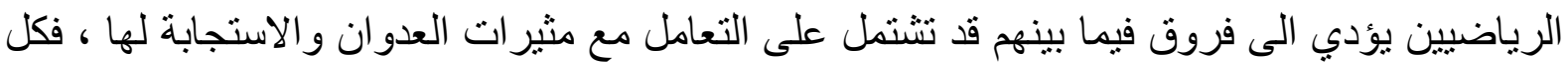

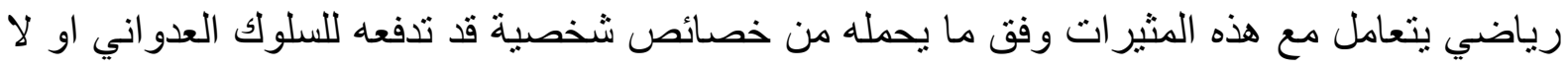

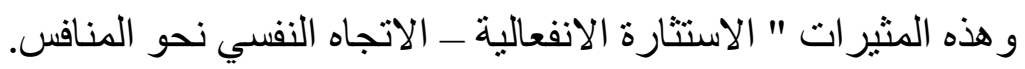
ويعزو الباحث ايضاً هذه العلاقة الى أن السلوك العدواني لدى لاعبي كرة اليد في العراق من خلال الجدول اعلاه تبين ان هناك علاقة ارتباط معنوية بين الضغوط النفسية والسلوك العدو اني لدى لاعبي كرة 
اليد حيث ان الخصائص المميزة للعبة كرة اليد وطبيعة قوانينها تبيح الاحتكاك المباشر بين اللاعبين وتساهم في ظهور السلوك العدواني وهذا ما اكده اسامة كامل راتب "ان الاحتكالك البدني بين اللاعبين اثناء المبار اة يسبب سلوكا عدوانيا في الالعاب المختلفة تبعا لمقدار الاحتكالك الذي تسببه طبيعة اللعبة وتسمح به قو انينها .

$$
\text { الإستخلاصات و التوصيات : }
$$

الإستخلاصات : الإنخات

• تحليل عبار ات مقياس الضغوط النفسية لدى لاعبى كرة اليد ويتضح حصول العبارة رقم (

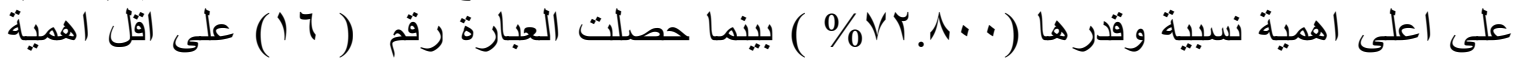

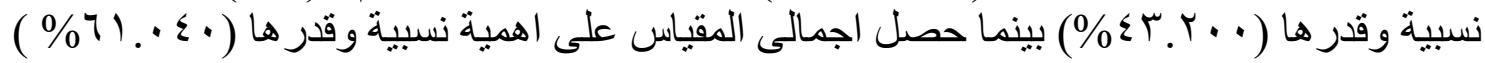

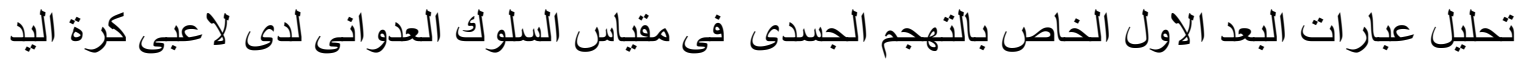

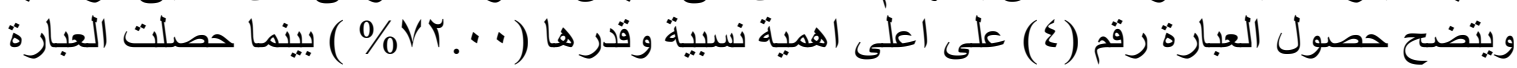

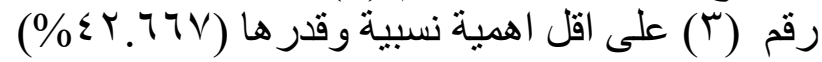

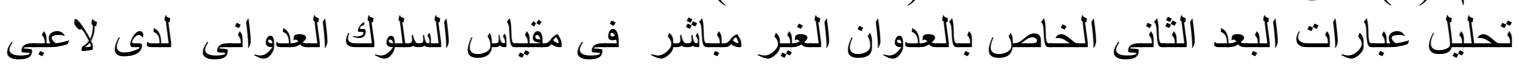

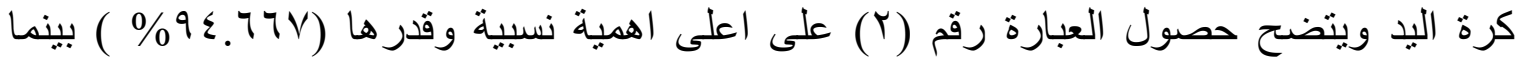

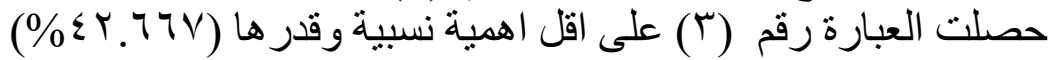

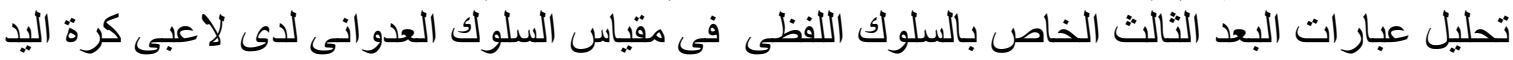

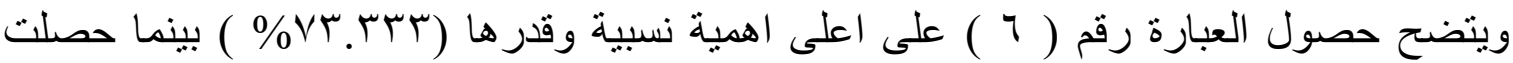

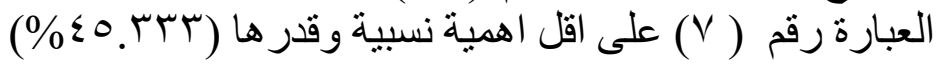

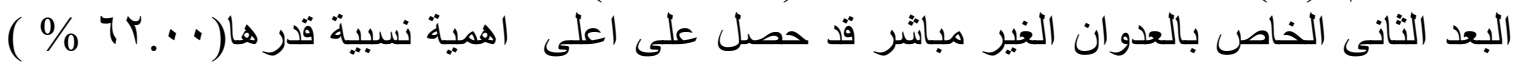

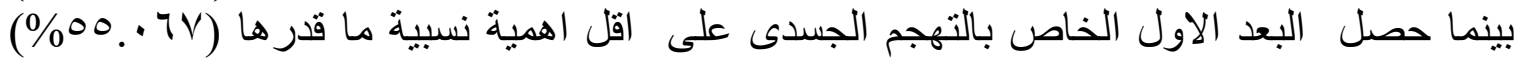

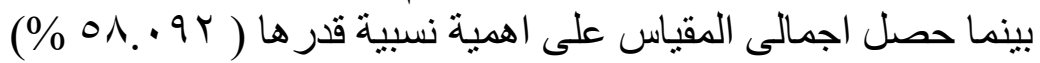

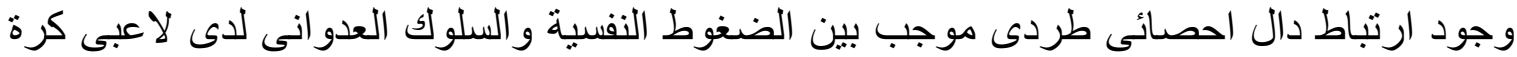

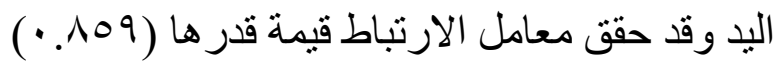

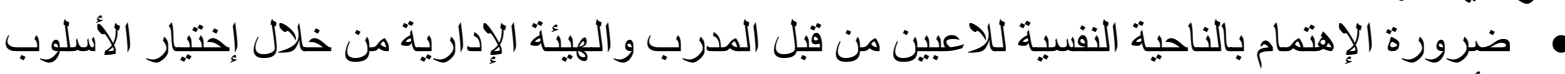

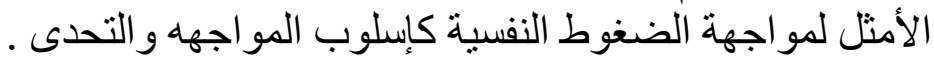
ضرورة تواجد مدرب نفسى لأهميته فى نجاح العملية التدريبية ومواجهة الحالات النفسية التى ولى التهوب

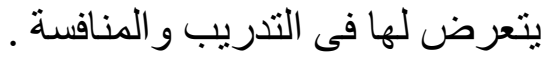
تو عية أسر اللاعبين من خلال الندوات واللقاءعات التأهمية المرحلة التى يعيشها أبنائهم و إيجابية الدور الذى يلعبونة فى الاسرة و المجتمع والدولة الته تو عية المدربين بضرورة الاهتمام بالاعداد النفسي للاعبين بجانب الأب الاعداد الاعداد المهاري و الخططي.

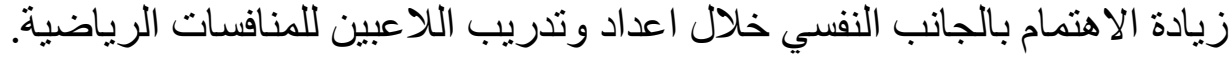

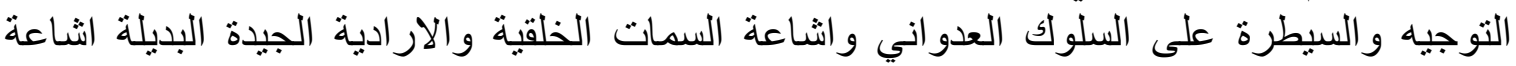
اللعب النظيف و الذي يعد من المقومات الاساسية للرياضة عدم اعطاء حمل تدريبي يفوق قدرة 


\section{المراجع العربية:}

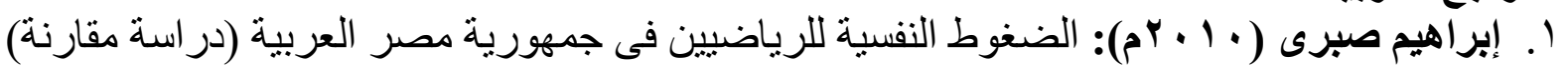

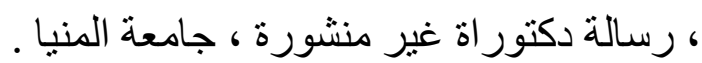

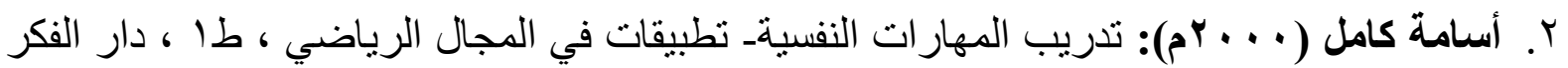

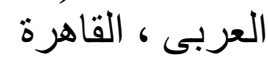

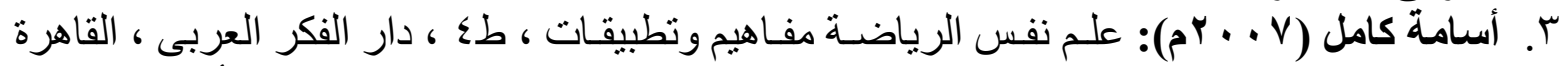

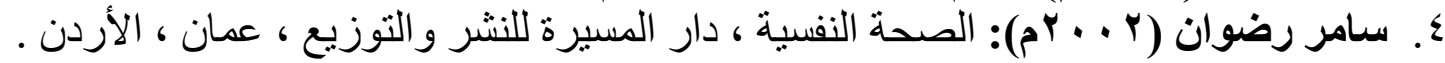

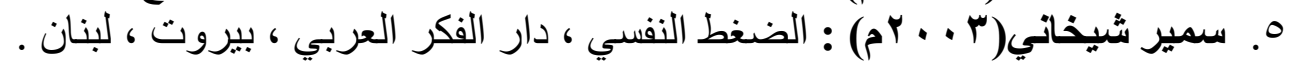

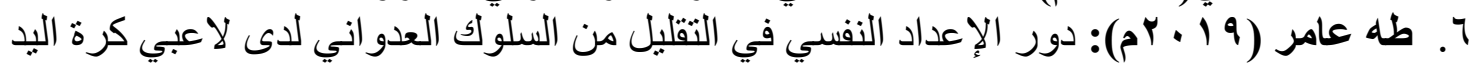

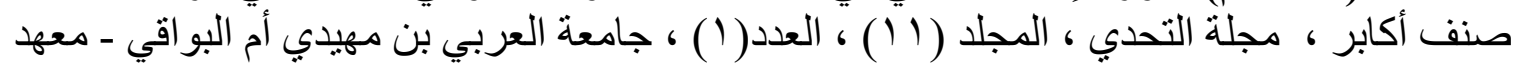

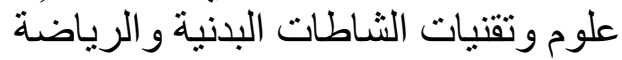

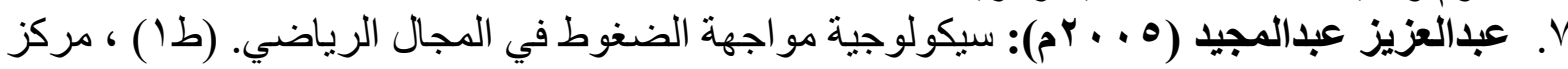
الكتاب للنشر ، القاهرة

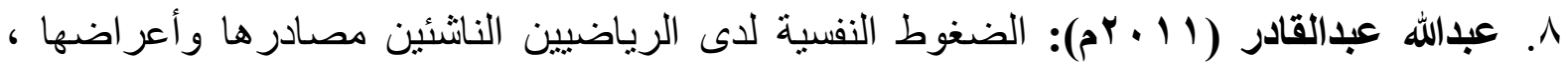

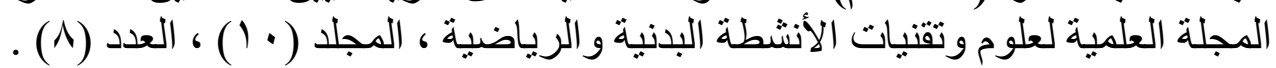

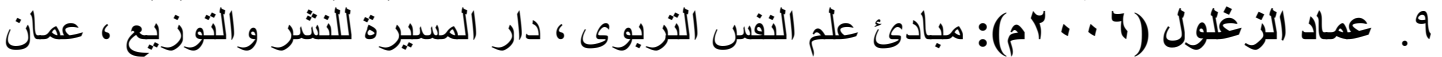

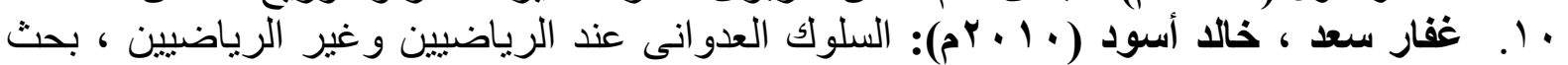

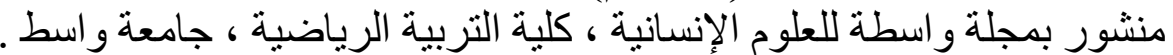

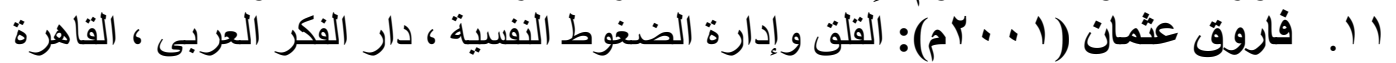

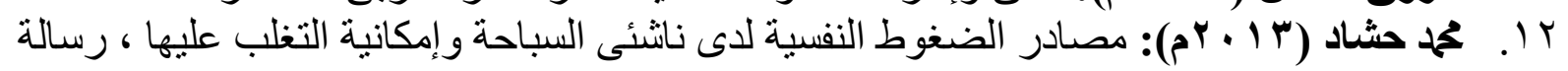

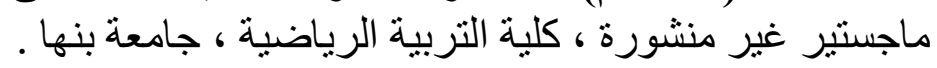

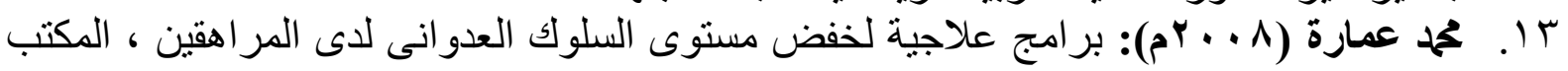

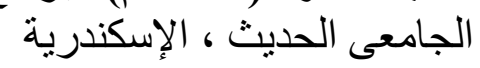

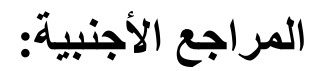

14. Dekovic (2003): Aggressive and Nonaggressive Antisocial Behavior in Adolescence, , Vol 93, Issue 2 , SAGE Publishing .

15. John W. Berry (2007): Acculturation strategies and adaptation, Queen's University, Kingston, Canada, K7L 3N6 .

16. Kassin, S. M., \& Gudjonsson, G. H. (2004): The Psychology of Confessions: A Review of the Literature and Issues. Psychological Science in the Public Interest, 5(2), 33-67.

17. Kelloway, K. and Barling, J. (2000): Job characteristic roles stress mental health. Journal of Occupational Psychology 10(3) .

18. Rozenblatt Shahal (2003): Advanced Psychological Assessment, P.C. , PHD, Long Island University, Springer, New York, NY . 
